UNIVERSIDADE DE SÃO PAULO

ESCOLA DE ENFERMAGEM

ISIS ARCANJO COLUCCI DA SILVA

O CONHECIMENTO DA CLASSIFICAÇÃO INTERNACIONAL DA ATENÇÃO PRIMÁRIA POR ENFERMEIROS DA ATENÇÃO PRIMÁRIA À SAÚDE

SÃO PAULO

2020 


\section{O CONHECIMENTO DA CLASSIFICAÇÃO INTERNACIONAL DA ATENÇÃO PRIMÁRIA POR ENFERMEIROS DA ATENÇÃO PRIMÁRIA À SAÚDE}

Dissertação apresentada ao Programa de Pós-Graduação Mestrado Profissional em Enfermagem na Atenção Primária no Sistema Único de Saúde da Escola de Enfermagem da Universidade de São Paulo para obtenção do título de Mestre em Ciências.

Área de concentração: Cuidados em Atenção Primária à Saúde

Orientadora: Prof ${ }^{\mathrm{a}}$. Dr ${ }^{\mathrm{a}}$. Anna Luiza de Fátima Pinho Lins Gryschek

\section{SÃO PAULO}


AUTORIZO A REPRODUÇÃO TOTAL OU PARCIAL DESTE TRABALHO, POR QUALQUER MEIO CONVENCIONAL OU ELETRÔNICO, PARA FINS DE ESTUDO E PESQUISA, DESDE QUE CITADA A FONTE.

Assinatura: Data: 1

Silva, Isis Arcanjo Colucci

O conhecimento da Classificação Internacional da Atenção Primária por enfermeiros da atenção primária à saúde /Isis Arcanjo Colucci da Silva. - São Paulo, 2020.

$79 \mathrm{p}$.

Dissertação (Mestrado) - Escola de Enfermagem da Universidade de São Paulo.

Orientadora: Prof ${ }^{a} \operatorname{Dr}^{a}$ Anna Luiza de Fátima Pinho Lins Gryschek

1. Classificação Internacional de Atenção Primária 2. Gestão da clínica 3. Enfermagem 4. Atenção Primária à Saúde. I. Título. 
Nome: Isis Arcanjo Colucci da Silva

Título: O conhecimento da classificação internacional da atenção primária por enfermeiros da atenção primária à saúde

Dissertação apresentada ao Programa de Pós-Graduação Mestrado Profissional em Enfermagem na Atenção Primária no Sistema Único de Saúde da Escola de Enfermagem da Universidade de São Paulo para obtenção do título de Mestre em Ciências.

Aprovado em:

\section{Banca Examinadora}

Orientador: Prof. Dr.

Instituição:

Assinatura:

Prof. Dr. Instituição

Julgamento: Assinatura:

Prof. Dr. Instituição

Julgamento: Assinatura:

Prof. Dr. Instituição

Julgamento: Assinatura:

Prof. Dr. Instituição

Julgamento: Assinatura: 


\section{APRESENTAÇÃO}

Aos 18 anos iniciei a graduação na Faculdade de Enfermagem da Universidade Paulista, tendo como objetivo atuar na Atenção Primária à Saúde, devido à convivência e empatia com profissionais que atuavam na área. A prática dos trabalhadores da Atenção Primária me encantava.

Minha primeira experiência profissional como enfermeira, ocorreu no Programa Saúde da Família do município de São Paulo, na Zona Sul, no ano de 2001, quando acontecia a transição do Plano de Atendimento à Saúde (PAS) para o Programa de Saúde da Família (PSF).

Neste mesmo ano realizei Especialização em Saúde Pública com ênfase no Programa de Saúde Família, na Universidade São Camilo, com o objetivo de aperfeiçoar a minha prática.

Oito anos depois aceitando novos desafios, atuei na gestão da Atenção Básica do município de Taboão da Serra.

Após um ano de pausa nas minhas atividades profissionais para me dedicar à maternidade, retornei ao trabalho numa Unidade Básica de Saúde (UBS) da Zona Oeste de São Paulo, onde trabalhei até meados 2019 como enfermeira da Estratégia de Saúde da Família (ESF) e acompanhando alunos de diversos cursos de graduação da Universidade de São Paulo (USP).

Em 2019, assumi a Coordenação da Atenção Primária à Saúde do Hospital Sírio Libanês.

Atualmente realizo Consultorias em Atenção Primária à Saúde.

Diante do desafio de qualificar o atendimento, melhorar o acesso dos pacientes ao serviço de saúde e qualificar o campo de ensino, me dediquei nos últimos anos a entender os processos de trabalho na Atenção Primária à Saúde.

Há 5 anos, implantamos o Acesso Avançado, o uso da SOAP (Subjetivo, Objetivo, Avaliação e Plano) e da Classificação Internacional da Atenção Primária (CIAP), diante das mudanças na organização do serviço, pude perceber que os profissionais têm pouca familiaridade para o uso destes instrumentos e que os alunos que acompanhamos não têm contato com essas ferramentas na Universidade.

A partir dos resultados deste projeto de pesquisa, espero poder oferecer subsídios para o aprimoramento da prática dos profissionais de saúde, em especial dos enfermeiros, além de produzir e disseminar conhecimentos na área de enfermagem e na saúde. 


\section{DEDICATÓRIA}

Dedico este trabalho a todos os enfermeiros, principalmente aos que eu pude ter o prazer de trocar experiências no ambiente de trabalho e ensino.

Ao meu marido, Carlos e minhas filhas Marjorie e Pietra, que em muitos momentos tiveram que compreender minha ausência, para me dedicar ao meu trabalho e meus estudos.

Dedico ainda aos pais Norma Sueli e Irio que sempre me incentivaram a estudar e me ensinaram a nunca desistir. 


\section{AGRADECIMENTOS}

Agradeço primeiramente a Deus por todos os meus sonhos alcançados.

Aos meus pais Sueli e Irio pessoas que sempre me apoiaram a estudar, que deixaram muitas vezes de lado seus próprios desejos para realizar os meus. Obrigada por tudo.

As minhas queridas filhas Marjorie e Pietra pelo entendimento e compreensão das minhas ausências.

Ao meu marido Carlos por me escutar, compreender e acolher nos momentos de angústia e indecisões.

A Profa. Dra. Anna Luiza, pela paciência, competência, seriedade e, especialmente, pelo carinho no cuidadoso processo de construção dessa dissertação. 
Meu Deus, meu Deus!

Como tudo é esquisito hoje!

E ontem tudo era exatamente como de costume.

Será que fui eu que mudei à noite?

Deixe-me pensar: eu era a mesma quando me levantei hoje de manhã?

Estou quase achando que posso me lembrar de me sentir um pouco diferente.

Mas se eu não sou a mesma, a próxima pergunta é: Quem é que eu sou?

Ah, essa é a grande charada!"

Alice no País das Maravilhas, de Lewis Carroll 
Silva IAC. O conhecimento da Classificação Internacional da Atenção Primária por enfermeiros da atenção primária à saúde [dissertação]. São Paulo: Escola de Enfermagem, Universidade de São Paulo; 2020.

\section{RESUMO}

Introdução: A classificação adequada para ser utilizada na Atenção Primária à Saúde (APS) é a Classificação Internacional de Atenção Primária (CIAP). Ela permite classificar o problema trazido pelo usuário de forma fidedigna, visto que dialoga com o método clínico centrado na pessoa e o Registro Clínico Orientado a Problemas (RCOP), que utiliza o método SOAP (Subjetivo, Objetivo, Avalição e Plano) de registro dos encontros e pressupõe uma caracterização dos motivos de consulta e problemas dos usuários. A CIAP tem sido recomendada pelo Ministério da Saúde (MS) desde 2013, sendo incorporada à ficha de atendimento individual no Sistema e-SUS Atenção Básica (e-SUS AB). A APS é a porta de entrada para o sistema de saúde, as ações devem ser desenvolvidas de forma contínua, com cuidado coordenado e abrangente. Para um trabalho eficiente é necessário avaliar as atividades que estão sendo realizadas de forma constante e a codificação do registro, contribuindo para a gestão da clínica e padronização dos dados para futuras pesquisas, portanto a acurácia das classificações é imprescindível. Não foram encontrados na literatura estudos que demonstrem o conhecimento e uso da CIAP por enfermeiros. Objetivo: Identificar o conhecimento da CIAP pelos enfermeiros, que atuam na APS. Método: $O$ estudo trata-se de uma pesquisa quantitativa, exploratória, a coleta de dados foi realizada através de um questionário eletrônico, tendo como público os enfermeiros que atuam na Atenção Primária à Saúde no Estado de São Paulo. Os dados foram coletados em duas partes: as características dos participantes e análise sobre o conhecimento e uso da CIAP. Resultados: Participaram da pesquisa 572 enfermeiros que atuavam na APS, 90,1\% sexo feminino e 9,9\% sexo masculino, com maior concentração de idade entre 31 e 45 anos. Observa-se maior número de formandos a partir do ano 2001, com acentuação nos anos de 2006 a 2010 e um crescimento significativo de alunos que cursaram Universidades Privadas entre 2006 e 2010, 76,88\% haviam cursado uma Universidade Privada e 23,12\% uma Universidade Pública. Dos respondentes $85,5 \%$ haviam realizado um curso ou mais de especialização, mestrado $11,8 \%$ e $2,8 \%$ de doutorado; $59,42 \%$ realizaram o curso em Universidades Privadas e 40,58\% em Universidades Públicas. Conheciam a CIAP, 87,2\% e utilizavam a CIAP 78,2\%. Dentre os profissionais que utilizavam a CIAP, a maioria utiliza a menos de seis anos, 70,6\% utilizam na Ficha de Produção. O momento em que os enfermeiros mais utilizam a CIAP é para classificar o Motivo de Consulta. Observou-se que $80,1 \%$ não haviam recebido treinamento, e 93,6\% entendem ser necessário serem treinados, 39,32\% gostariam de receber o treinamento de forma presencial e 44,34\% por aula on-line. Como produto dessa pesquisa desenvolveu-se uma proposta de um curso EAD para instrumentalizar os profissionais quanto ao conhecimento e o uso da CIAP. Conclusão: Observa-se que um número expressivo de enfermeiros está utilizando a CIAP, porém sem um conhecimento aprofundado da sua aplicabilidade e estrutura. Acredita-se que após o treinamento os profissionais poderão realizar codificações com um grau de acurácia confiável, podendo então esses dados serem utilizados para pesquisas e gestão da clínica.

PALAVRAS-CHAVE: Classificação Internacional de Atenção Primária. Gestão da clínica. Enfermagem. Atenção Primária à Saúde. 
Silva IAC. Knowlegde of the Internacional Classification of Primary Care for diseases of primary heakth care. [dissertation]. São Paulo: School of Nursing, Universidad de São Paulo; 2020.

\begin{abstract}
Introduction: The appropriate classification to be used in Primary Health Care (PHC) is the International Classification of Primary Care (CIAP). It allows to classify the problem brought by the user in a reliable way, since it dialogues with the person-centered clinical method and the Problem Oriented Clinical Record (RCOP), which uses the SOAP method (Subjective, Objective, Assessment and Plan) of registering patients. meetings and presupposes a characterization of the reasons for consultation and users' problems. The CIAP has been recommended by the Ministry of Health (MS) since 2013, being incorporated into the individual care record in the e-SUS Primary Care System (e-SUS AB). PHC is the gateway to the health system, actions must be developed continuously, with coordinated and comprehensive care. For an efficient work it is necessary to evaluate the activities that are being carried out constantly and the codification of the record, contributing to the management of the clinic and standardization of the data for future research, therefore the accuracy of the classifications is essential. No studies have been found in the literature that demonstrate the knowledge and use of CIAP by nurses. Objective: To identify the knowledge of CIAP by nurses, who work in PHC. Method: The study is a quantitative, exploratory research, the data collection was carried out through an electronic questionnaire, with the public working with nurses working in Primary Health Care in the State of São Paulo. The data were collected in two parts: the characteristics of the participants and analysis on the knowledge and use of the CIAP. Results: 572 nurses who worked in PHC participated in the research, $90.1 \%$ female and $9.9 \%$ male, with a higher concentration of age between 31 and 45 years. A greater number of trainees is observed from the year 2001, with an accentuation in the years 2006 to 2010 and a significant growth of students who attended Private Universities between 2006 and 2010, 76.88\% had attended a Private University and $23.12 \%$ a Public University. Of the respondents $85.5 \%$ had taken a specialization course or more, a master's degree, $11.8 \%$ and $2.8 \%$ a doctorate; $59.42 \%$ took the course at Private Universities and $40.58 \%$ at Public Universities. They knew the CIAP, $87.2 \%$ and used the CIAP 78.2\%. Among the professionals who used the CIAP, the majority used it for less than six years, $70.6 \%$ used it in the Production Form. The moment when nurses use CIAP the most is to classify the Reason for Consultation. It was observed that $80.1 \%$ had not received training, and $93.6 \%$ believed it necessary to be trained, $39.32 \%$ would like to receive the training in person and $44.34 \%$ by online class. As a product of this research, a proposal for a distance learning course was developed to provide professionals with the knowledge and use of the CIAP. Conclusion: It is observed that a significant number of nurses are using the CIAP, but without a thorough knowledge of its applicability and structure. It is believed that after training, professionals will be able to perform coding with a reliable degree of accuracy, and this data can then be used for research and clinic management.
\end{abstract}

KEYWORDS: International Classification of Primary Care. Clinical governance. Primary health care. Nursing. 


\section{LISTA DE FIGURAS}

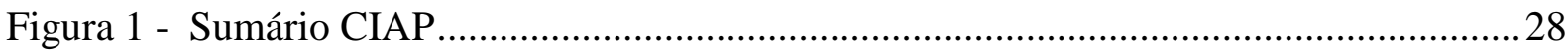

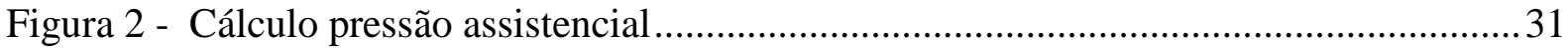

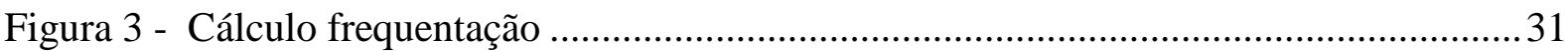

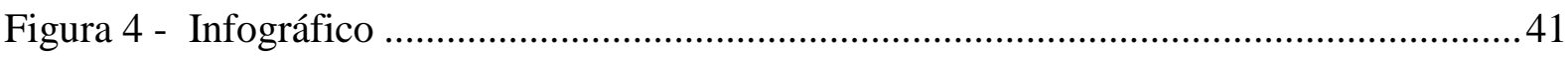




\section{LISTA DE GRÁFICOS}

Gráfico 1 - Distribuição dos Enfermeiros quanto à idade 48

Gráfico 2 - Distribuição dos enfermeiros quanto ao ano de conclusão da graduação e tipo de Universidade. 49

Gráfico 3 - Distribuição dos Enfermeiros por ano de conclusão da Pós Graduação e tipo de

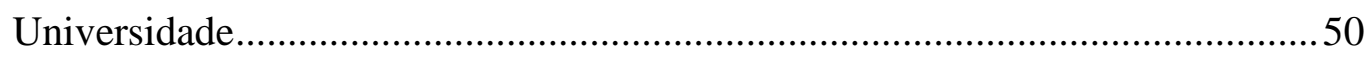

Gráfico 4 - Distribuição quanto ao tempo de uso da CIAP ..................................................52

Gráfico 5 - Distribuição quanto aos momentos em que os Enfermeiros utilizavam a CIAP .53

Gráfico 6 - Distribuição da preferência de modelo de treinamento no CIAP 55 


\section{LISTA DE QUADROS}

Quadro 1 - Distribuição dos Enfermeiros de São Paulo por faixa etária.................................37

Quadro 2 - Distribuição dos Enfermeiros de São Paulo quanto ao sexo ................................ 37

Quadro 3 - Distribuição dos enfermeiros de São Paulo quanto a faixa etária ......................... 38

Quadro 4 - Distribuição dos enfermeiros de São Paulo quanto a nacionalidade....................38

Quadro 5 - Distribuição dos enfermeiros de São Paulo quanto a natureza da instituição

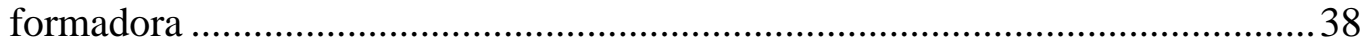

Quadro 6 - Distribuição dos enfermeiros de São Paulo quanto a realização de pós-graduação

Quadro 7 - Distribuição dos enfermeiros de São Paulo que realizaram pós-graduação por modalidade 


\section{LISTA DE SIGLAS}

\begin{tabular}{|c|c|}
\hline APS & Atenção Primária à Saúde \\
\hline CDS & Coleta de Dados Simplificada \\
\hline CEP & Comitê de Ética em Pesquisa \\
\hline CIAP & Classificação Internacional da Atenção Primária \\
\hline CID & Classificação Internacional de Doenças \\
\hline CMC & Classificação de Motivo de Consulta \\
\hline DAB & Departamento de Atenção Básica \\
\hline ESF & Estratégia de Saúde da Família \\
\hline e-SUS AB & Sistema e-SUS Atenção Básica \\
\hline ICPC & International Classification in Primary Care \\
\hline INAMPS & Instituto Nacional de Assistência Médica da Previdência Social \\
\hline MS & Ministério da Saúde \\
\hline OMS & Organização Mundial da Saúde \\
\hline OSS & Organização Social de Saúde \\
\hline PUSF & Programa Unidade de Saúde da Família \\
\hline RCOP & Registro Clínico Orientado por Problema \\
\hline SAS & Secretaria de Atenção à Saúde \\
\hline SBMFC & Sociedade Brasileira de Medicina de Família e Comunidade \\
\hline SIAB & Sistema de Informação da Atenção Básica \\
\hline SISAB & Sistema de Informação em Saúde para a Atenção Básica \\
\hline SMS-SP & Secretaria Municipal da Saúde de São Paulo \\
\hline SOAP & Subjetivo, Objetivo, Avaliação e Plano \\
\hline SPDM & Associação Paulista para o Desenvolvimento da Medicina \\
\hline SUS & Sistema Único de Saúde \\
\hline TCLE & Termo de Consentimento Livre e Esclarecido \\
\hline UBS & Unidade Básica de Saúde \\
\hline USP & Universidade de São Paulo \\
\hline WICC & Wonca Internacional Classification Committee \\
\hline WONCA & World Organization of National Colleges, Academies and Academic \\
\hline
\end{tabular}




\section{SUMÁRIO}

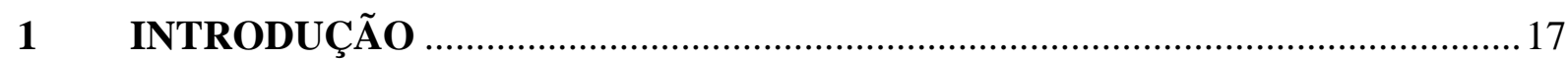

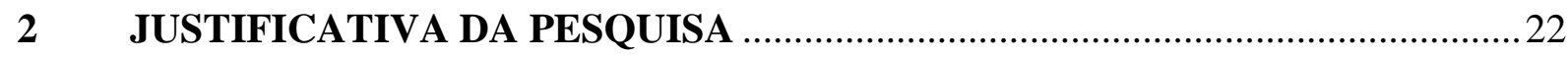

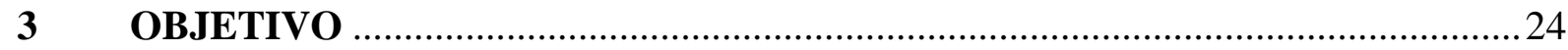

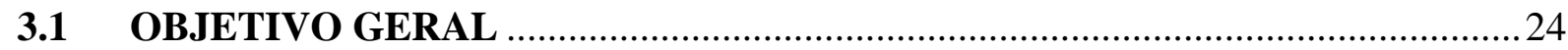

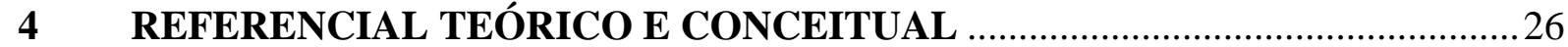

4.1 CLASSIFICAÇÃO INTERNACIONAL EM ATENÇÃO PRIMÁRIA (CIAP) ...26

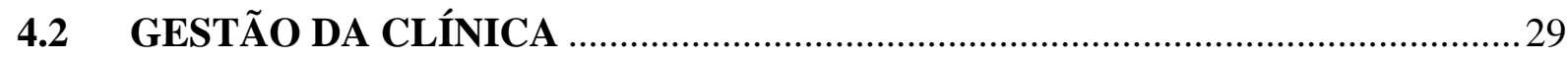

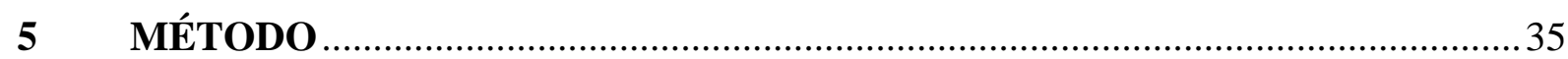

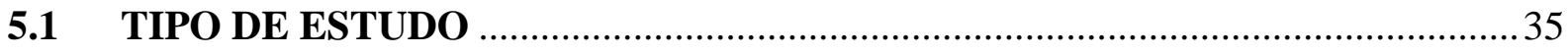

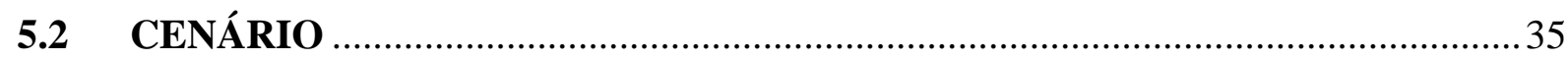

5.3 POPULAÇÃO E AMOSTRA DO ESTUDO ………………………………....... 36

5.4 PROCEDIMENTOS METODOLÓGICOS ……………………………........... 40

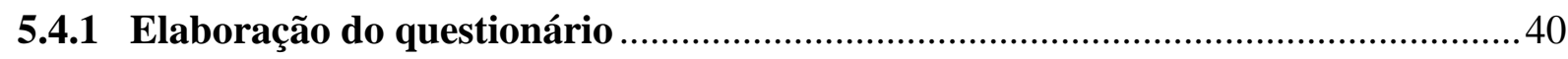

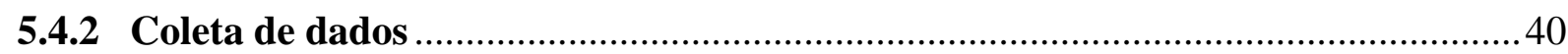

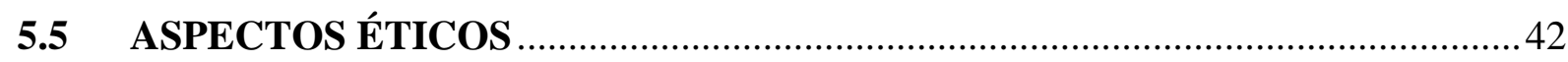

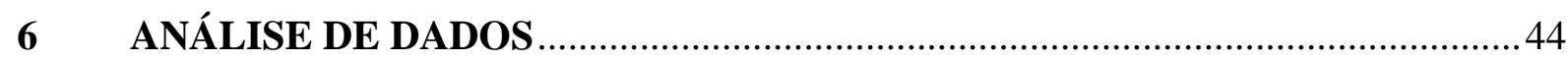

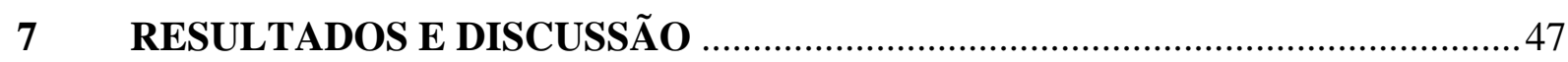

7.1 CARACTERIZAÇÃO DOS PARTICIPANTES..................................................4

7.2 ANÁLISE DO CONHECIMENTO E USO DA CIAP ………………………….......

7.3 PRODUTO DESENVOLVIDO A PARTIR DA PESQUISA - LINHAS GERAIS PARA O DESENVOLVIMENTO DE UM CURSO EAD SOBRE CIAP PARA

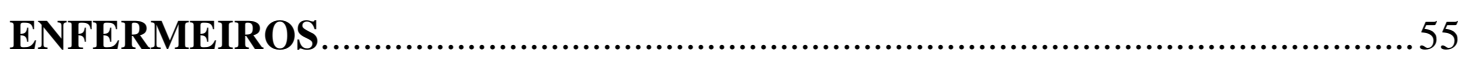

8 CONCLUSÃO

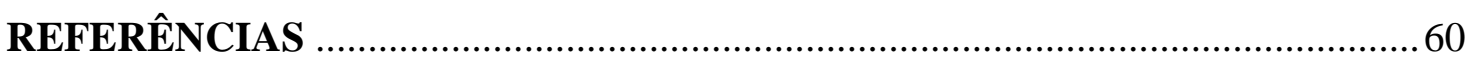

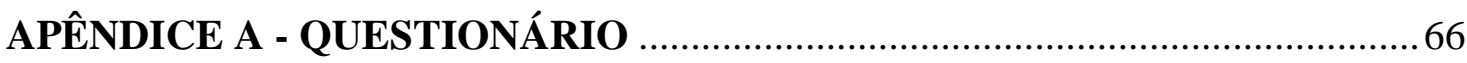

ANEXO A - CLASSIFICAÇÃO INTERNACIONAL DE ATENÇÃO PRIMÁRIA

ANEXO B - FICHA DE ATENDIMENTO INDIVIDUAL …………………….....

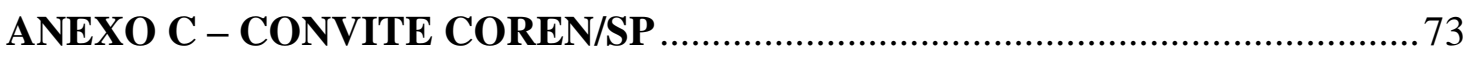

ANEXO D - TERMO DE CONSENTIMENTO LIVRE E ESCLARECIDO -

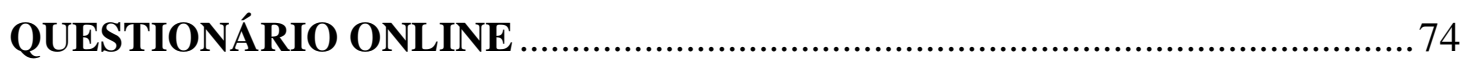


ANEXO E - CAPACITAÇÃO PARA CONHECIMENTO E APLICABILIDADE

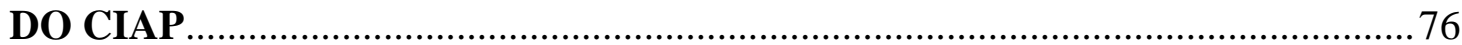




\section{INTRODUÇÃO}

Em 1978, na Conferência de Alma Ata, firmou-se a Atenção Primária à Saúde (APS) como estratégia prioritária para ampliar o acesso à saúde $\mathrm{e}^{(1)}$.

No Brasil, a orientação para a APS se deu a partir da introdução do Sistema Único de Saúde (SUS) e da Estratégia de Saúde da Família (ESF), objetivando ações individuais e coletivas no espectro que compreende desde a promoção à saúde até a reabilitação, incluindo a redução de danos e considerando a abrangência integral dos indivíduos, em todos os ciclos de $\operatorname{vida}^{(2)}$.

A APS é um dos locais prioritários para o primeiro contato do paciente com o sistema de saúde, sendo que neste nível de atenção as ações devem ser realizadas de forma contínua, com cuidado coordenado e abrangente. Diversos estudos comprovam que os sistemas de saúde orientados para APS são mais custo-efetivos, mesmo em contextos de grande iniquidade social $^{(3)}$.

A longitudinalidade é um dos atributos essenciais na APS, sendo o acompanhamento do indivíduo realizado de forma contínua e a longo prazo, propiciando conhecê-lo de forma abrangente, estreitanto suas relações e fortalecendo o vínculo. Para garantir este atributo, de uma forma que não fique personalizado no profissional que realiza os atendimentos é necessário que os registros dos casos sejam fidedignos ao estado de saúde do indivíduo e sejam realizados com qualidade, pois eles possibilitarão a análise dos dados para a gestão da clínica, a coordenação do cuidado e o trabalho multiprofissional ${ }^{(4,5)}$.

Para uma gestão da clínica eficiente, faz-se necessário avaliar o trabalho desenvolvido pelos profissionais da APS de forma constante, visando o planejamento dos processos de trabalho, para a melhoria dos resultados e satisfação dos indivíduos e profissionais envolvidos. Quando esse processo é seguido podemos conhecer a demanda, os motivos pelos quais as pessoas procuram o serviço, seus diagnósticos e as possíveis intervenções a serem propostas ${ }^{(4)}$.

Na APS, os registros e a organização da clínica têm particularidades desse modelo de atenção à saúde, que diferem dos modelos utilizados na atenção secundária e terciária à saúde, são levados em consideração dados importantes de saúde e gestão clínica, na atenção centrada no paciente.

O sistema de classificação mais conhecido e utilizado é a Classificação Internacional de Doenças (CID), ele é focado na identificação de causas de mortalidade e morbidade, não considerando o contexto ao qual o usuário pertence, seus sentimentos, sua rede de apoio e suas 
expectativas, fatores que na APS são de suma importância, além de ser uma classificação de uso exclusivo dos profissionais médicos ${ }^{(4,6)}$.

Levando-se em conta as especificidades da APS, o modelo atualmente mais adequado de sistematização dos atendimentos tem sido o Registro Clínico Orientado a Problemas (RCOP), que utiliza o método SOAP de registro da evolução clínica. ${ }^{(39)}$

O registro utilizando o método SOAP, pressupõe uma caracterização dos motivos de consulta e dos problemas dos pacientes, que transcende o método tradicional de classificação de queixas da CID. Nesse sentido, tem sido adotada em diversos serviços a Classificação Internacional de Atenção Primária (CIAP) (ANEXO A), que por ter sido pensada para esse contexto, permite avaliar o motivo da consulta trazido pelo paciente e relacioná-lo com o método clínico centrado na pessoa ${ }^{(7)}$.

O uso da CIAP tem sido recomendado no Brasil pelo Ministério da Saúde (MS) desde 2013, é um item de preenchimento obrigatório que se encontra no atual Sistema de Informação em Saúde da Atenção Básica (SISAB) ${ }^{(8)}$.

Em 2013, o Departamento de Atenção Básica (DAB), da Secretaria de Atenção à Saúde (SAS), do Ministério da Saúde (MS) reestruturou o Sistema de Informação da Atenção Básica (SIAB), visando melhorar a qualidade da informação em saúde e o seu uso pelos gestores, profissionais de saúde e cidadãos ${ }^{(8)}$.

A operacionalização do SISAB foi feita por meio da estratégia do Departamento de Atenção Básica (DAB/SAS/MS) denominada e-SUS Atenção Básica (e-SUSAB) e a Portaria No 1.412, de 10 de julho de 2013 - Institui o Sistema de Informação em Saúde para a Atenção Básica (SISAB) ${ }^{(8)}$.

O e-SUS Atenção Básica (e-SUS AB) é uma estratégia do Ministério da Saúde através do Departamento de Atenção Básica (DAB) para reestruturar as informações da atenção primária à saúde (APS), modernizando sua plataforma tecnológica com o objetivo de informatizar as unidades básicas de saúde, oferecer ferramentas para ampliar o cuidado e melhorar o acompanhamento da gestão. ${ }^{(8)}$

Os instrumentos de registro dos atendimentos foram reformulados, dentre eles a ficha de atendimento individual (ANEXO B) que é destinada aos profissionais de nível superior e tem como objetivo coletar dados dos atendimentos realizados ${ }^{(8)}$.

O e-SUS AB é composto por dois sistemas de software que podem operar desde uma Unidade Básica de Saúde (UBS) sem computador, através do sistema de Coleta de Dados Simplificado (CDS) e do uso de fichas, até Unidades com algum grau de informatização com a utilização do Prontuário Eletrônico do Cidadão (PEC). Ambos os softwares alimentam o SISAB 
e possibilitam atender aos diversos cenários e informatização e conectividade das unidades de AB no Brasil ${ }^{(8)}$.

Esta ficha deve ser digitada no sistema de software no campo de Coleta de Dados Simplificada (CDS), para alimentação da base nacional de dados, de acordo com a Portaria de Alimentação do SISAB do ano vigente ${ }^{(8)}$.

Ela é composta de dados como:

- Tipo de atendimento: consulta agendada programada/consulta de cuidado continuado, demanda espontânea, consulta no dia, atendimento de urgência;

- Avaliação antropométrica;

- Crianças: tipo de aleitamento;

- Gestantes: Data da última menstruação e Idade gestacional;

- Atendimento domiciliar e Bloco de problemas/condição avaliada ${ }^{(8)}$.

O bloco de problemas/condição avaliada deve ser utilizado para registrar os problemas/condições de saúde avaliados e manejados pelo profissional de saúde no momento do atendimento ${ }^{(8)}$.

Para este registro poderão ser utilizadas as seguintes classificações: a CIAP (Classificação Internacional de Atenção Primária) e a CID 10 (Classificação Internacional de Doenças $)^{(8)}$.

O RCOP e a CIAP podem ser utilizados por todos os profissionais que atuam na Atenção Primária à Saúde. A CIAP é estruturada de forma a priorizar a localização anatômica, o que faz com que seja facilmente implementada e possa ser usada pela equipe multiprofissional que compartilha a responsabilidade nos atendimentos ${ }^{(9)}$.

Em pesquisa ao Conselho Regional de Enfermagem de São Paulo, quanto ao uso do CIAP, o mesmo se posiciona favorável ao uso no PARECER COREN-SP 010/2015, Ementa: Uso da Classificação Internacional da Atenção Primária (CIAP) por Enfermeiros que atuam em Atenção Primária e Estratégia Saúde da Família.

Da Conclusão

Diante do exposto, concluímos que a Classificação Internacional em Atenção Primária (CIAP-2) é um item de preenchimento obrigatório que se encontra no atual Sistema de Informação em Saúde da Atenção Básica (e-SUS/SISAB) e poderá ser utilizada como um sistema de classificação de problemas, complementando os demais sistemas de classificação diagnóstica utilizados pelos Enfermeiros, (NANDA-I, CIPE® ou CIPESC®). A CIAP-2 oferece nomenclaturas que contemplam todas as profissões, cabendo ao Enfermeiro utilizar as classificações no âmbito de sua atuação profissional, o que não significa a substituição do diagnóstico de enfermagem. Vale ressaltar que o Prontuário Eletrônico do Cidadão (PEC) garante campo para utilização das classificações de linguagem de enfermagem, indispensáveis para atender ao 
previsto na Resolução COFEN 358/2009, que dispõe sobre a Sistematização da Assistência de Enfermagem e a implementação do Processo de Enfermagem em ambientes, públicos ou privados, em que ocorre o cuidado profissional de Enfermagem.

Por tratar-se de um sistema de classificação pouco conhecido por Enfermeiros na Atenção Básica, recomendamos a capacitação dos profissionais para a utilização da CIAP-2 ${ }^{(10)}$.

Um dos problemas enfrentados quando se implementa um sistema de classificação é a dificuldade de compreensão e codificação similar pelos diferentes atores envolvidos. O uso de várias terminologias pode dificultar a comparação e a análise dos dados entre serviços, sendo necessário, desta maneira, implementar uma padronização que permitisse maior precisão na obtenção de $\operatorname{dados}^{(11)}$.

Além da melhora na obtenção de dados, que viabiliza a avaliação dos resultados e intervenções influenciando na qualidade do cuidado prestado, o uso destas classificações e instrumentos contribuem para a assistência, melhorando a comunicação entre a equipe multiprofissional $^{(11)}$.

Após extensa pesquisa de revisão bibliográfica, auxiliada por uma bibliotecária, nas bases de dados científicas foi possível observar que diversos países da Europa, Ásia, América, África e Oceania estão utilizando a CIAP.

Os estudos que aparecem nas pesquisas estão relacionados com o uso da codificação dos motivos de consultas e diagnósticos para uma avaliação do perfil de atendimento, porém não foram encontrados estudos que relatassem o conhecimento dos enfermeiros da Atenção Primária à Saúde em relação a CIAP.

Portanto, este estudo pretende responder à seguinte pergunta de pesquisa:

Qual o conhecimento que os enfermeiros da Atenção Primária à Saúde têm em relação à CIAP? 
2 JUSTIFICATIVA DA PESQUISA 


\section{JUSTIFICATIVA DA PESQUISA}

O uso da CIAP ou do CID10 tem sido uma exigência do Ministério da Saúde desde 2013. É um item de preenchimento obrigatório que se encontra no atual Sistema de Informação em Saúde da Atenção Básica, este dado faz parte da ficha de atendimento individual que é utilizada para gerar a produção dos profissionais ${ }^{(8)}$.

Diante da exigência de se usar uma das Classificações para o preenchimento da Ficha Individual, levando -se em consideração que a CID é de uso exclusivo dos profissionais médicos, e que a mesma não contempla as especificidades da APS, acredita-se que os enfermeiros que atuam na APS estejam fazendo uso da CIAP para realizar o preenchimento dessa ficha.

Embora se tenha adotado a CIAP como uma possível classificação para o Sistema de Informação da Atenção Básica, poucos estudos têm avaliado o conhecimento para sua utilização pelos profissionais envolvidos. Esse conhecimento e a qualidade destes dados são de suma importância para a gestão da clínica, entendendo ser imprescindível realizar diagnósticos e codificações com boa acurácia para propor planos de cuidados adequados aos pacientes. Diante da ausência de estudos, acredita-se ser importante identificar o conhecimento sobre a utilização da CIAP pelos enfermeiros da APS. 


\section{OBJETIVO}

\subsection{OBJETIVO GERAL}

Identificar o conhecimento da CIAP pelos enfermeiros que atuam na APS. 
4 REFERENCIAL TEÓRICO E CONCEITUAL 


\section{REFERENCIAL TEÓRICO E CONCEITUAL}

\subsection{CLASSIFICAÇÃO INTERNACIONAL EM ATENÇÃO PRIMÁRIA (CIAP)}

Em 1978, na Conferência Internacional de Alma Ata, a Organização Mundial de Saúde (OMS) e a World Organization of National Colleges, Academies and Academic Associations of General Practitioners/Family Physicians (WONCA), entenderam que seria necessário para obter sistemas de cuidados primários adequados, que os profissionais da APS tivessem acesso às informações precisas, por novos sistemas de classificação ${ }^{(12)}$.

Diante disso, um grupo de trabalho da OMS, inicialmente desenvolveu uma Classificação Internacional que foi chamada de Classificação de Motivos de Consulta (CMC), e que mais tarde seria a base para o desenvolvimento da CIAP ou ICPC, do termo em inglês International Classification in Primary Care ${ }^{(12)}$.

A WONCA, publicou a primeira edição da CIAP em 1987. Apesar da CIAP-1 fazer mais sentido para APS do que as classificações anteriores, ela não contava com critérios de inclusão para as rubricas ou qualquer tipo de referência cruzada e não estabelecia uma ligação com a $10^{\text {a }}$ edição da CID-10, então no ano de 1995, foi publicada a segunda edição que permitia essas condições ${ }^{(12)}$.

Em 2006, o Brasil passou a ter um representante no Comitê Internacional de Classificação da WONCA (WICC), representado na pessoa do Dr. Gustavo Diniz Ferreira Gusso.

Até este momento pesquisadores brasileiros utilizavam a versão de Portugal, porém não era suficiente para o uso sistematizado em prontuários eletrônicos ou para classificar todos os encontros entre profissionais da APS e os pacientes ${ }^{(12)}$.

O MS assinou então um convênio com a Sociedade Brasileira de Medicina de Família e Comunidade (SBMFC), que viabilizou o pagamento dos royalties para a WONCA e o livre uso da CIAP no Brasil ${ }^{(12)}$.

Algumas adaptações em relação à versão portuguesa foram decididas, o próprio nome, que em Portugal era Classificação Internacional de Cuidados Primários; na versão brasileira, foi substituído "cuidados" por "atenção", termo mais utilizado no Brasil ${ }^{(12)}$.

Foi realizada uma revisão minuciosa dos termos e as adaptações necessárias e duas alterações de rubricas efetivadas; o termo A77 passou a ser "Dengue e outras doenças virais NE" em vez de "Outras doenças virais NE" onde se incluía a dengue e o A78 "Hanseníase e 
outras doenças infecciosas NE" em vez de "Outras doenças infecciosas NE" que incluía a hanseníase ${ }^{(12)}$.

Esta foi uma maneira de dar destaque para estes problemas de saúde que não estavam explicitados na rubrica nas versões inglesa e portuguesa, mas apenas nos critérios de inclusão, considerando a importância dessas doenças no contexto nacional.

A CIAP está estruturada por episódios de cuidado, pensando episódio de cuidado como todo tipo de assistência prestada a um indivíduo que apresente um problema ou uma necessidade de saúde, desde o primeiro encontro até o último encontro com o profissional e por este motivo podendo durar uma consulta ou mais, e podendo nunca se encerrar ${ }^{(6)}$.

Para cada encontro três elementos são essenciais: os motivos de consulta, o diagnóstico ou problema encontrado e o processo de cuidado (intervenção ou procedimento). Todos esses elementos são codificados pela $\operatorname{CIAP}^{(12)}$.

O motivo da consulta é um elemento importante no registro, ele se dá a partir das informações que o paciente traz, ou seja, o motivo que o fez procurar o serviço de saúde deve ser classificado da forma como o paciente o expressa e deve estar claro tanto para o paciente, como para o profissional, que o registrará com a rubrica mais apropriada na classificação. Quando houver mais de um problema, todas os motivos de consulta deverão ser registrados ${ }^{(7)}$.

Pode-se encontrar como motivo de encontro uma variedade de situações como, a solicitação de um laudo, uma renovação de uma receita, uma dúvida sobre saúde/doença ou um sintoma. Diante do uso da Classificação de Motivos de Consulta entendeu-se que poderia ser possível e necessário se codificar outros momentos da consulta; o problema e as intervenções ${ }^{(4)}$.

A CIAP apresenta-se com um código alfanumérico de uma letra e dois numerais. É dividida em dezessete capítulos, por sistemas, incluindo o psicológico, a gravidez e o planejamento familiar, problemas sociais e um capítulo de situações gerais e não específicas ${ }^{(12)}$.

Os capítulos estão divididos em sete subseções: queixas e sintomas, procedimentos e diagnósticos preventivos, medicações, tratamentos e terapêutica, resultados de exames, componente administrativo, acompanhamento e outros motivos de consultas e de diagnósticos e doenças, estas divididas em infecciosas, neoplasias, lesões, anomalias congênitas e outras ${ }^{(12)}$. 
Figura 1 - Sumário CIAP

\section{CAPITULOSE COMPONENTES DA CIAP*}

A Geral e năo-especifico

B Sangue, órgáos hematopoiéticos e linfáticos (baço, medula óssea)

D Aparelho digestivo

F Olhos

H Ouvidos

K Aparelho circulatório

L Sistema musculoesquelético

N Sistema nervoso

P Psicológico

R Aparelho respiratorio

$S$ Pele

T Endócrino, metabólico e nutricional

U Aparelho urinário

W Gravidez e planejamento familiar

$X \quad$ Aparelho genital feminino (incluindo mama)

Y Aparelho genital masculino

Z Problemas sociais

\section{Componentes (Iguals para todos os capitulos)}

1 Componente de queixas e sintomas

2 Componente de procedimentos diagnosticos e preventivos

3 Componente de medicaçōes, tratamentos e procedimentos terapeuticos

4 Componente de resultados de exames

5 Componente administrativo

6 Componente de acompanhamento e outros motivos de consulta

7 Componente de diagnósticos e doenças, incluindo:

- doenças infecciosas

- neoplaslas

- lesōes

- anomalias congenitas

- outras doenças especificas

"Sempre que possivel, fol utilizado um código alfa mnemonico.

Fonte: Comitê Internacional de Classificação da WONCA ${ }^{(12)}$.

A CIAP inclui cerca de 200 sintomas/queixas e 300 diagnósticos comuns na APS. Quase todos apresentam uma incidência de pelo menos 1 para cada 1000 pacientes/ano ${ }^{(12)}$.

A utilização da CIAP-2, conforme já citado anteriormente, é um item da ficha individual de atendimento, de preenchimento obrigatório que se encontra no atual Sistema de Informação em Saúde da Atenção Básica ${ }^{(8)}$. 


\subsection{GESTÃO DA CLÍNICA}

Segundo Mendes, que utilizou essa expressão pela primeira vez em 2001, a gestão da clínica pode ser definida como a tecnologia de microgestão dos serviços de saúde, tendo a finalidade de assegurar padrões clínicos ótimos, de aumentar a eficiência, de diminuir os riscos para os usuários e para profissionais, de prestar serviços efetivos e de melhorar a qualidade da atenção à saúde ${ }^{(13)}$.

No Brasil foi instaurada uma tradição de se trabalhar por programas, pois antes da Constituição de 1988 e da implantação do Sistema Único de Saúde (SUS) a assistência era realizada pelo Instituto Nacional de Assistência Médica da Previdência Social (INAMPS) e era de responsabilidade do Ministério da Saúde as ações programáticas. Esta desagregação entre a vigilância à saúde e a assistência foi absorvida nos modelos de atenção, portanto a gestão da clínica pode colaborar para a superação desta lacuna ${ }^{(14)}$.

A APS é o primeiro nível da assistência à saúde, a porta de entrada preferencial para a rede de atenção à saúde e onde deve ser organizado o acesso aos demais níveis do sistema, espera-se nesse nível uma resolubilidade de 85 a $95 \%$ dos problemas de saúde. Os problemas menos frequentes são encaminhados para o nível secundário, enquanto o nível terciário realiza $\mathrm{o}$ atendimento de casos mais $\operatorname{raros}^{(5)}$.

Os atributos da APS podem ser divididos em quatro: acesso, longitudinalidade, coordenação e abrangência e é a partir desses atributos que a gestão da prática clínica deve ser $\operatorname{organizada}^{(3)}$.

Acesso: a demanda de uma população adscrita não será diminuída com o tempo, mas poderá ser organizada ${ }^{(15)}$.

A busca por atendimento de saúde segundo estimativas internacionais (Inglaterra e Estados Unidos) sugerem que a cada mil habitantes, cerca de 250 indivíduos procuram atendimento de saúde no período de um mês ${ }^{(16)}$.

Fatores relacionados ao perfil dos usuários como pouca rede social, baixos níveis socioeconômico e educacional, alto índice de morbidades (maior causa preditora em vários estudos), alto índice de quadros de saúde mental, desemprego, mulheres em torno dos 40 anos, idade acima dos 65 anos, e dinâmicas familiares disfuncionais influenciam significativamente a utilização dos serviços de saúde ${ }^{(15)}$.

Considerando o atributo de primeiro contato, a APS não pode ser considerada somente o lugar da prevenção e do seguimento ambulatorial de quadros crônicos; ela também é lugar de urgências e de quadros agudos ${ }^{(17)}$ 
O modelo de agendamento pode reprimir sua real demanda, influenciando de forma direta a utilização do serviço ${ }^{(15)}$. Para exemplificar podemos citar: tempo de espera (tanto de agendamento quanto em sala de espera), distância e condições de transporte até a unidade de saúde, organização do serviço, e relação funcionário - cliente como fatores que podem ser importantes à procura por atendimento.

Em 1971, Hart descreveu a lei dos cuidados inversos, que diz que a melhor assistência médica está disponível para a população que menos precisa dela, fazendo-se necessário redistribuir o cuidado para a população que mais se beneficiaria do mesmo ${ }^{(18)}$.

Não é incomum identificar na APS serviços que oferecem assistência de forma que os grupos entendidos como prioridades ocupam grande parte da carga assistencial. À essa população é ofertado um excesso de consultas e de procedimentos, enquanto as pessoas com queixas agudas ou que não se enquadram nas definidas prioridades precisam procurar outras instâncias do serviço de saúde ${ }^{(13,17)}$.

Um serviço de APS de qualidade deveria oferecer o acesso mais ampliado possível às pessoas; para que elas procurassem a unidade quando sentissem necessidade; deveria indicar a periodicidade dos retornos de forma criteriosa, e a pessoa escolheria voltar no dia que fosse mais interessante para ela própria; pensando também na corresponsabilidade do cuidado e na diminuição da taxa de absenteísmo; identificar indivíduos com alta vulnerabilidade e alto risco, e pouca autonomia fazendo a vigilância do cuidado e facilitando o contato dos mesmos com o serviço, de forma a buscar equidade ${ }^{(17)}$.

Longitudinalidade: A longitudinalidade pode ocorrer através do conhecimento do território e população pelo profissional que está atuando ou por registros. Quando este atributo se faz presente, o tempo de consulta tende a diminuir e os atendimentos se tornam mais eficientes, possibilitando ofertar mais encontros à mesma pessoa durante $\mathrm{o}$ ano ${ }^{(17)}$.

Pode-se verificar que muitas vezes o termo "continuidade do cuidado" é utilizado com significado semelhante ao de longitudinalidade.

Em um estudo de revisão bibliográfica realizado para definir o termo longitudinalidade e continuidade do cuidado, a autora faz uma discussão onde podemos verificar que não existe um consenso entre os autores. No presente trabalho vamos adotar os termos como similares ${ }^{(19)}$.

Coordenação do cuidado: a coordenação do cuidado baseia-se numa relação equilibrada entre diversos profissionais e serviços com o objetivo de obter-se uma atenção integral e de qualidade ao usuário. Para alcançar-se uma coordenação do cuidado resolutiva alguns pontos são importantes: a informação, a clínica e a administração/organização ${ }^{(20)}$. 
Ter informações sobre o usuário é fundamental para dar continuidade e integrar os profissionais no seu acompanhamento. A clínica é a ferramenta que permite que os profissionais da APS possam dar seguimento ao cuidado e organizem o acesso e as informações dos outros níveis de atenção. As questões administrativas são importantes para a organização e integração da rede de atenção, definindo processos de trabalho, entre os níveis do sistema de saúde ${ }^{(20)}$.

A coordenação do cuidado deve ser compartilhada entre os membros da equipe. Usando o trabalho em equipe, entre médico e enfermeiro numa ESF, é possível aumentar a eficiência no manejo dos casos, e distribuir a carga de trabalho entre os diferentes profissionais ${ }^{(17)}$.

Os agentes comunitários de saúde e os auxiliares de enfermagem também podem ter um papel diferente e mais dinâmico na coordenação dos casos com uma escuta acolhedora, continência, e vigilância sobre casos selecionados ${ }^{(17)}$.

Para a organização da clínica que visa um cuidado de qualidade é necessário entender a demanda, tanto de forma quantitativa, como de forma qualitativa ${ }^{(15)}$.

A gestão da demanda deve ser pensada visando a redistribuição e racionalização das atividades de modo que as respostas possam ser atendidas pelo profissional mais eficiente e capacitado para resolver o problema ${ }^{(17)}$.

Uma das formas quantitativas de se avaliar a demanda é o binômio pressão assistencialfrequentação, que nos permite avaliar as possibilidades e limitações dos serviços para uma possível reorganização.

Usualmente, essas são as medidas para análise quantitativa da demanda, normalmente calculadas para o período de um ano.

Figura 2 - Cálculo pressão assistencial

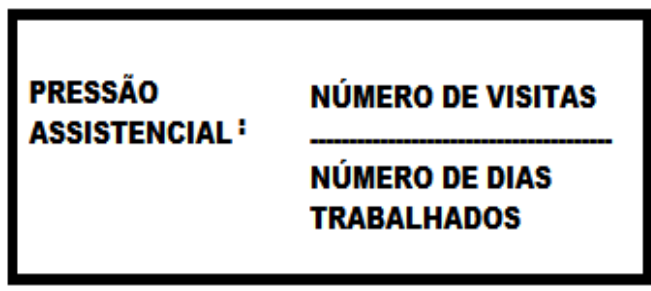

Fonte: Casajuana e Bellón ${ }^{(15)}$.

Figura 3 - Cálculo frequentação 


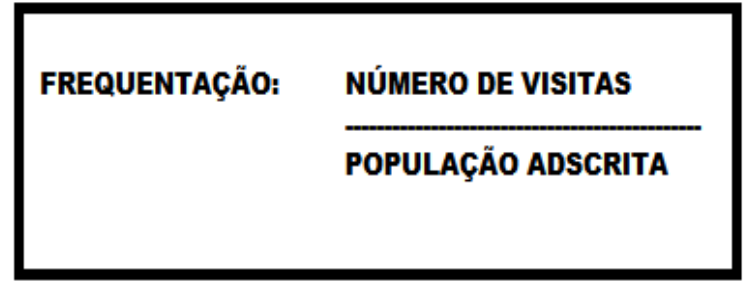

Fonte: Casajuana e Bellón ${ }^{(15)}$.

Internacionalmente, sugere-se como adequadas uma pressão assistencial média de 25 atendimentos por dia, e uma frequentação entre 3 e 4 consultas por habitante por ano ${ }^{(15)}$.

Para aprimorar a avaliação da demanda, realizar uma análise qualitativa é de grande importância.

As demandas podem ser: assistenciais ou administrativas; previsíveis ou imprevisíveis.

As atividades administrativas previsíveis (laudos, renovação de receitas de crônicos, impressos para programas como auto-monitoramento glicêmico, benefícios, entre outros) correspondem a cerca de $40 \%$ da demanda de um serviço de APS $^{(21)}$.

As necessidades assistenciais previsíveis (seguimento de crônicos estáveis, resultados de exames, rotina de "saudáveis" como pré-natal e puericultura) são o segundo grupo mais prevalente de demandas na $\operatorname{APS}^{(17)}$.

O papel de protagonismo do enfermeiro nas necessidades assistenciais previsíveis tem grande coerência, quando se considera que uma gestão adequada da demanda, prioriza que a resposta seja dada pelo profissional com mais disponibilidade para tal, esta reposta a um problema pode estar na área de intersecção de conhecimentos e habilidades de mais de uma categoria profissional ${ }^{(22)}$.

Para contemplar as demandas imprevisíveis pelo serviço de saúde é necessário organizar as agendas de forma que essas demandas interfiram o mínimo possível nas atividades programadas, sem que haja a necessidade de criar vias paralelas para suprir essa demanda ${ }^{(17)}$.

Integralidade ou Abrangência: Para realizar-se um cuidado integral a equipe de saúde deve estar preparada para lidar com a diversidade de necessidades em saúde dos indivíduos, da família ou das comunidades seja resolvendo-os, o que pode ocorrer em $85 \%$ das situações, ou referindo-os a outros pontos de atenção à saúde, que podem ser aos cuidados secundários, terciários, ou a setores como a educação, assistência social e habitação entre outros ${ }^{(3)}$.

Este conceito parte do entendimento ampliado da saúde, levando em conta necessidades biológicas, psicológicas e sociais, reconhecendo também aspectos culturais e subjetividades do 
indivíduo, seu grupo de suporte primário e todo seu contexto comunitário, ainda integrando promoção, prevenção e tratamento à prática clínica e comunitária ${ }^{(23)}$.

O trabalho com a equipe interdisciplinar é de grande importância na APS para que se contemple a integralidade, devido a diversidade e complexidade da assistência, necessitando de intervenções de forma coordenada com diversas especialidades. 


\section{MÉTODO}

\subsection{TIPO DE ESTUDO}

Trata-se de uma pesquisa quantitativa, exploratória, descritiva, transversal, realizada por meio da aplicação de um questionário eletrônico.

De acordo com Minayo ${ }^{(24)}$, os métodos quantitativos têm o objetivo de mostrar dados, indicadores e tendências observáveis, ou produzir modelos teóricos abstratos com elevada aplicabilidade prática. Suas investigações evidenciam a regularidade dos fenômenos ${ }^{(24)}$.

A pesquisa quantitativa, que se apoia no positivismo lógico, tem uma tendência a evidenciar o raciocínio dedutivo, os princípios da lógica e as características mensuráveis da vivência humana ${ }^{(25)}$.

As pesquisas exploratórias são aquelas realizadas em áreas e sobre problemas sem informação do tema em que se deseja conhecer o fenômeno, proporcionando maiores informações sobre o assunto que vai ser investigado ${ }^{(26)}$.

Estudos exploratórios possibilitam ao pesquisador aproximar-se de um objeto de pesquisa ainda pouco conhecido, com o objetivo de explorar seus significados e o contextos da investigação, buscando aprofundar o conhecimento em torno da realidade ${ }^{(27)}$.

Este tipo de estudo exploratório pretende explorar e busca a descoberta de um fenômeno, o estudo descritivo retrata ou descreve as características de indivíduos, de situações ou de grupos, mostrando a frequência com que ocorrem determinados fenômenos e o estabelecimento das relações entre as variáveis identificadas ${ }^{(25)}$.

O Mestrado Profissional em Enfermagem na Atenção Primária à Saúde busca colaborar com a elucidação das ações das práticas em saúde, podendo promover prováveis problemas de pesquisa e contribuindo para possíveis soluções.

\subsection{CENÁRIO}

Os dados foram coletados no Estado de São Paulo, em uma parceria com o Conselho Regional de Enfermagem de São Paulo (COREN-SP) para o envio do questionário eletrônico aos enfermeiros do Estado de São Paulo.

O Estado de São Paulo é o mais populoso do Brasil. 
De acordo com as estimativas populacionais da Fundação SEADE (novembro de 2018), o estado de São Paulo possui 43.993.159 habitantes, distribuídos em 645 municípios espalhados por uma área territorial de $248.209,3 \mathrm{~km}^{2(28)}$.

As mulheres constituem a maior parte da população paulista. Estima-se que a população feminina é de 22.583.800 habitantes, e a masculina é de 21.409 .359 habitantes $^{(28)}$.

São Paulo é o Estado com a maior concentração de indústrias e com grande diversidade de atividades produtivas, sendo assim, economicamente o mais rico do país. O PIB é constituído (46\%) pelas atividades industriais, (47\%) pelo setor de comércio e serviços e (7\%) por uma atividade agropecuárias ${ }^{(28)}$.

Em 2009 haviam 14215 estabelecimentos hospitalares, com 95.585 leitos.

Em 2013, 98,76\% da população paulista tinha acesso à rede de água, 94,87\% tinha acesso à rede de esgoto sanitário e 99,89\% tinha serviço de coleta de lixo ${ }^{(28)}$.

Dados de uma pesquisa realizada pelo IBGE em 2008, revelam que $81,3 \%$ da população paulista avalia sua saúde como boa ou muito boa; $72,7 \%$ da população realiza consulta médica periodicamente; $45,2 \%$ dos habitantes consultam o dentista regularmente e 6,5\% da população esteve internado em leito hospitalar nos últimos doze meses. 33,7\% dos habitantes declararam ter alguma doença crônica e apenas 40,1\% tinham plano de saúde. Outro dado significante é o fato de 28,9\% dos habitantes declararem necessitar sempre do Programa Unidade de Saúde da Família-PUSF ${ }^{(28)}$.

\subsection{POPULAÇÃO E AMOSTRA DO ESTUDO}

O Estado de São Paulo conta com 135.486 enfermeiros inscritos no COREN-SP até a data de 01/02/2020. Dentre estes profissionais a maioria é do sexo feminino, totalizando $(87,14 \%)$, e do sexo masculino (12,86\%). A faixa etária predominante é de 30 a 39 anos com $41,2 \%{ }^{(29)}$. 
Quadro 1 - Distribuição dos Enfermeiros de São Paulo por faixa etária

\begin{tabular}{|c|c|}
\hline Faixa Etária & \% \\
\hline 70 e mais & 0,7 \\
\hline 60 a 69 & 4,2 \\
\hline 50 a 59 & 12,3 \\
\hline 40 a 49 & 29,9 \\
\hline 30 a 39 & 41,2 \\
\hline 20 a 29 & 11,4 \\
\hline
\end{tabular}

Fonte: Coren - $\mathrm{SP}^{(29)}$.

Em 2013 foi realizado pela Cofen/Fiocruz uma pesquisa para traçar o perfil dos Enfermeiros no Brasil ${ }^{(30)}$.

Neste estudo foram entrevistados 105.438 Enfermeiros no Estado de São Paulo, elucidando dados importantes para o conhecimento da amostra estudada ${ }^{(30)}$.

Alguns dados serão apresentados a seguir.

Quadro 2 - Distribuição dos Enfermeiros de São Paulo quanto ao sexo

\begin{tabular}{|c|c|}
\hline Sexo & $\boldsymbol{\%}$ \\
\hline Masculino & 12,8 \\
\hline Feminino & 86,6 \\
\hline
\end{tabular}

Fonte: Cofen/Fiocruz ${ }^{(30)}$. 
Quadro 3 - Distribuição dos enfermeiros de São Paulo quanto a faixa etária

\begin{tabular}{|c|c|}
\hline Faixa etária & \% \\
\hline Até 25 anos & 5,4 \\
\hline $26-30$ anos & 17,9 \\
\hline $31-35$ anos & 22,4 \\
\hline $36-40$ anos & 16,6 \\
\hline $41-45$ anos & 11,4 \\
\hline $46-50$ anos & 11,5 \\
\hline $51-55$ anos & 8,4 \\
\hline $56-60$ anos & 3,9 \\
\hline $61-65$ anos & 1,6 \\
\hline $66-69$ anos & 0,3 \\
\hline 70 anos e mais & 0,1 \\
\hline NR & 0,5 \\
\hline Aposentadoria (Mais de 61 anos) & 2 \\
\hline
\end{tabular}

Fonte: Cofen/Fiocruz ${ }^{(30)}$.

Quadro 4 - Distribuição dos enfermeiros de São Paulo quanto a nacionalidade

\begin{tabular}{|c|c|}
\hline Nacionalidade & $\%$ \\
\hline Brasileira & 98,7 \\
\hline Estrangeira & 0,5 \\
\hline
\end{tabular}

Fonte: Cofen/Fiocruz ${ }^{(30)}$.

Quadro 5 - Distribuição dos enfermeiros de São Paulo quanto a natureza da instituição formadora

\begin{tabular}{|c|c|}
\hline Instituição & \% \\
\hline Pública & 24,8 \\
\hline Privada & 68 \\
\hline Filantrópica & 4,9 \\
\hline Outra & 0,1 \\
\hline NR & 2,3 \\
\hline
\end{tabular}

Fonte: Cofen/Fiocruz ${ }^{(30)}$. 
Quadro 6 - Distribuição dos enfermeiros de São Paulo quanto a realização de pós-graduação

\begin{tabular}{|c|c|}
\hline Pós-Graduação & \% \\
\hline Sim & 80,8 \\
\hline Não & 16,8 \\
\hline NR & 2,3 \\
\hline
\end{tabular}

Fonte: Cofen/Fiocruz ${ }^{(30)}$.

Quadro 7 - Distribuição dos enfermeiros de São Paulo que realizaram pós-graduação por modalidade

\begin{tabular}{|c|c|}
\hline Modalidade & \% \\
\hline Residência & 5,4 \\
\hline Especialização & 73,2 \\
\hline Mestrado Profissional & 3,5 \\
\hline Mestrado Acadêmico & 11,3 \\
\hline Doutorado & 5,9 \\
\hline Pós-doutorado & 0,7 \\
\hline
\end{tabular}

Fonte: Cofen/Fiocruz ${ }^{(30)}$.

Para esse estudo serão considerados os seguintes critérios de inclusão e exclusão:

Inclusão:

- $\quad$ Estar cadastrado no COREN-SP até 01/02/2020

- $\quad$ Ter e mail ativo no COREN-SP

- Realizar o aceite do TCLE

Exclusão:

- $\quad$ Aqueles que não aceitaram o TCLE

- $\quad$ Os respondentes que não atuassem na APS 


\subsection{PROCEDIMENTOS METODOLÓGICOS}

\subsubsection{Elaboração do questionário}

Os procedimentos adotados se iniciaram com a elaboração de um questionário (APÊNDICE A).

O questionário foi desenvolvido pela pesquisadora com base em pesquisas bibliográficas sobre a CIAP. Outras contribuições importantes para a construção do questionário foram a experiência da própria autora em sua prática assistencial e sugestões dos doutores na área durante o exame de qualificação.

O questionário foi composto por 3 fases:

Primeira fase: triagem dos profissionais, se atuavam na APS;

Segunda fase: Caracterização dos participantes,

Terceira fase: Elucidação do conhecimento e uso do CIAP pelos Enfermeiros da Atenção Primária à Saúde do Estado de São Paulo.

\subsubsection{Coleta de dados}

A pesquisa foi realizada por meio de um questionário eletrônico, através da ferramenta Google Forms.

A pesquisadora realizou uma reunião com um conselheiro do COREN-SP, afim de apresentar o projeto de pesquisa e solicitar seu envio a partir da lista de cadastro do órgão.

Após aprovação do COREN-SP, os participantes receberam por e-mail, enviado pelo COREN-SP, um convite explicativo para participação da pesquisa nos meses de fevereiro a março de 2020 (ANEXO C). 
Figura 4 - Infográfico

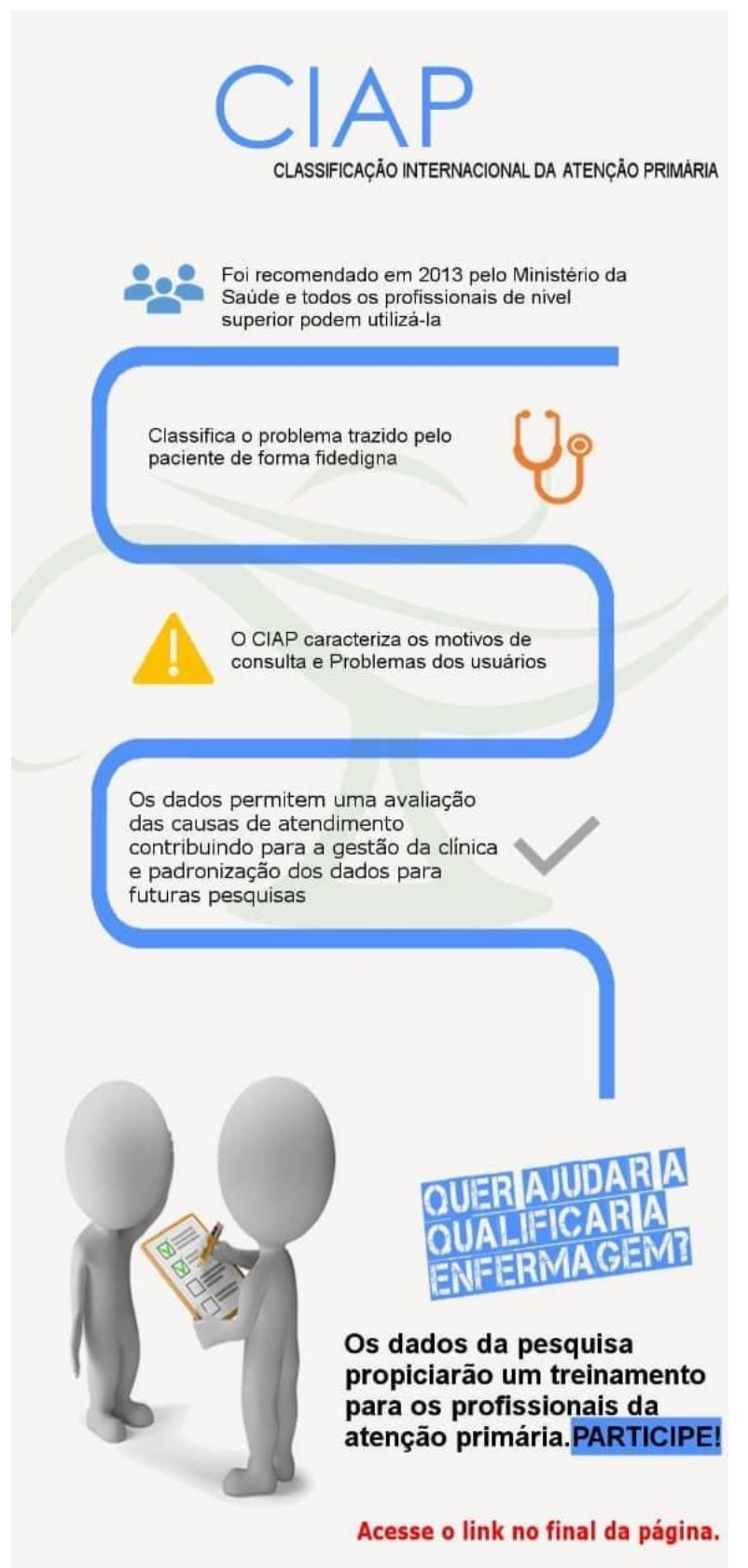

Fonte: Autoria própria

A participação se iniciava por meio de um link de acesso ao questionário eletrônico onde a primeira ação foi a solicitação de leitura do Termo de Consentimento Livre Esclarecido (TCLE) (ANEXO D).

Os sujeitos que concordaram em participar da pesquisa, na primeira tela indicaram obrigatoriamente que realizaram a leitura do TCLE e assinalaram que concordam em participar 
da pesquisa. Desta forma não foi necessário a assinatura do TCLE e envio posterior para o pesquisador pelos participantes.

Ao consentir o sujeito foi direcionado a uma nova etapa onde respondeu se era um profissional que atuava na APS, a fim de restringir a amostra aos profissionais que não atuavam na APS.

Caso o enfermeiro não atuasse, foi enviada uma mensagem agradecendo a participação e o preenchimento do questionário eletrônica era encerrado.

A primeira parte do questionário era composta por perguntas para a caracterização dos participantes da pesquisa quanto ao sexo, idade, tempo de graduação, titulação e instituição onde atuava.

Posteriormente as questões eram direcionadas para a elucidação do conhecimento da CIAP dos enfermeiros da Atenção Primária à Saúde do Estado de São Paulo.

\subsection{ASPECTOS ÉTICOS}

O projeto de pesquisa foi submetido à apreciação do Comitê de Ética em Pesquisa (CEP) da Escola de Enfermagem da Universidade de São Paulo e foi aprovado em 17/10/2019. Foram observados todos os preceitos éticos que envolvem pesquisa com seres humanos, de acordo com a Resolução 466/2012.

Os profissionais responderam um questionário online, antes de iniciar o preenchimento do mesmo anuíram em sua participação através do TCLE Online, sendo que a indicação de aceite foi realizada no próprio formulário online e foi condição obrigatória para que o participante tivesse acesso ao formulário. 
6 ANÁLISE DE DADOS 


\section{ANÁLISE DE DADOS}

A análise dos dados foi realizada de forma quantitativa.

A análise de dados tem como finalidade elucidar os dados coletados tendo em vista os aspectos sociais, históricos e filosóficos no período da coleta e anteriores à ela e procura ampliar o conhecimento adquirido sobre o tema estudado ${ }^{(24)}$.

O método quantitativo tem como objetivo demostrar dados, indicadores e tendências observáveis ou produzir modelos teóricos de alta abstração com aplicabilidade prática ${ }^{(24)}$.

Como ferramenta para a análise de dados quantitativos foi utilizada a estatística descritiva.

Um banco de dados foi construído e analisado pelo Microsoft Excel 2010, utilizando-se a distribuição absoluta e relativa das respostas relacionadas às variáveis estudadas.

Para melhor visualização e compreensão dos dados foram apresentados por meio de ilustração com gráficos.

Para a presente pesquisa foi realizado um levantamento do quantitativo de profissionais de enfermagem do Estado de São Paulo, inscritos no COREN-SP, e com e-mail ativo.

A coleta de dados foi realizada entre os meses de fevereiro e março de 2020. A população do estudo foi constituída por 133.414 enfermeiros do Estado de São Paulo, que estavam inscritos no COREN- SP até o dia 01/02/2020 e com e-mail válido. Foram estabelecidos como critérios de inclusão: estar inscrito no COREN-SP até 01 fevereiro de 2020 e ter um e mail válido cadastrado no COREN-SP.

Após discussão com profissional estatístico, para a determinação da amostra, foi realizado o cálculo para estimativa do tamanho amostral, considerando a fórmula para população infinita, e sem reposição dos indivíduos investigados, com 95\% de confiança e erro de $5 \%$, considerando estimativa da proporção igual a 50\%. Foi obtido tamanho de amostra igual a 384 para atender ao requisito estatístico de validade. Nesse sentido, fizeram parte da amostra 572 enfermeiros do Estado de São Paulo. 


$$
\text { Tamanho da amostra }=\frac{\frac{z^{2} \times p(1-p)}{e^{2}}}{1+\left(\frac{z^{2} \times p(1-p)}{e^{2} N}\right)}
$$

$\mathrm{N}=$ tamanho da população $\bullet \mathrm{e}=$ margem de erro (porcentagem no formato decimal) $\bullet \mathrm{z}=$ escore $\mathrm{z}$

Do total de 133.414 enfermeiros do Estado de São Paulo cadastrados no COREN-SP e com e mail ativo elegíveis, acessaram a pesquisa 1.319 enfermeiros, foram excluídos 734 por não serem enfermeiros que atuam na APS, 10 por não aceitarem as condições do termo de consentimento e 3 por não terem terminado a graduação.

Dessa forma, participaram deste estudo 572 enfermeiros do Estado de São Paulo. 
7 RESULTADOS E DISCUSSÃO 


\section{RESULTADOS E DISCUSSÃO}

\subsection{CARACTERIZAÇÃO DOS PARTICIPANTES}

Do total de 1319 enfermeiros respondentes, 734 atuavam em outras áreas, não sendo elegíveis para a presente pesquisa, 10 não aceitaram o termo de consentimento e 3 foram excluídos por não terem concluído a graduação, portanto 572 enfermeiros atuavam na APS podendo colaborar com a pesquisa.

Aos que confirmaram que atuavam na APS, foi dado continuidade ao preenchimento do questionário, iniciando com a caracterização dos participantes e após as perguntas sobre o conhecimento e uso da CIAP.

$\mathrm{Na}$ primeira parte do questionário constam perguntas para a caracterização do profissional entre elas: características sociodemográficas e de formação, como: Idade, Sexo, Instituição e ano de Graduação, Instituição e ano de Pós-Graduação, local onde atua.

A partir dos dados sociodemográficos, observou-se que os participantes desse estudo eram predominantemente do sexo feminino.

Dentre os 572 enfermeiros do Estado de São Paulo respondentes, encontrou-se 90,1\% de pessoas do sexo feminino e $9,9 \%$ do sexo masculino.

No que se refere à predominância do sexo feminino, o estudo corrobora para a feminilização da profissão, primeiro por historicamente as profissões de cuidado estarem relacionadas às mulheres e também pelo aumento da inserção de mulheres em Cursos de Nível Superior ${ }^{(31)}$.

Em pesquisa realizada pela FioCruz para caracterização profissional, podemos observar que $(87,14 \%)$ dos enfermeiros eram do sexo feminino e $(12,86 \%)$ do sexo masculino, convergindo com os dados encontrados nesta pesquisa ${ }^{(30)}$.

A faixa etária predominante é de 30 a 39 anos com $41,2 \%{ }^{(29)}$.

De forma global, estudos internacionais destacam a crescente inserção das pessoas do sexo feminino com menos de 30 anos no mundo do trabalho, com destaque para a Enfermagem na área de saúde ${ }^{(32)}$.

Quanto à distribuição por idade, tem-se observado uma distribuição linear entre 31 e 45 anos, uma idade relativamente jovem, no entanto considerando o envelhecimento do perfil populacional brasileiro, que vem crescendo de forma exponencial, vale um alerta para a importância de cuidados e formação dessa categoria profissional ${ }^{(33)}$. 
Gráfico 1 - Distribuição dos enfermeiros quanto à idade

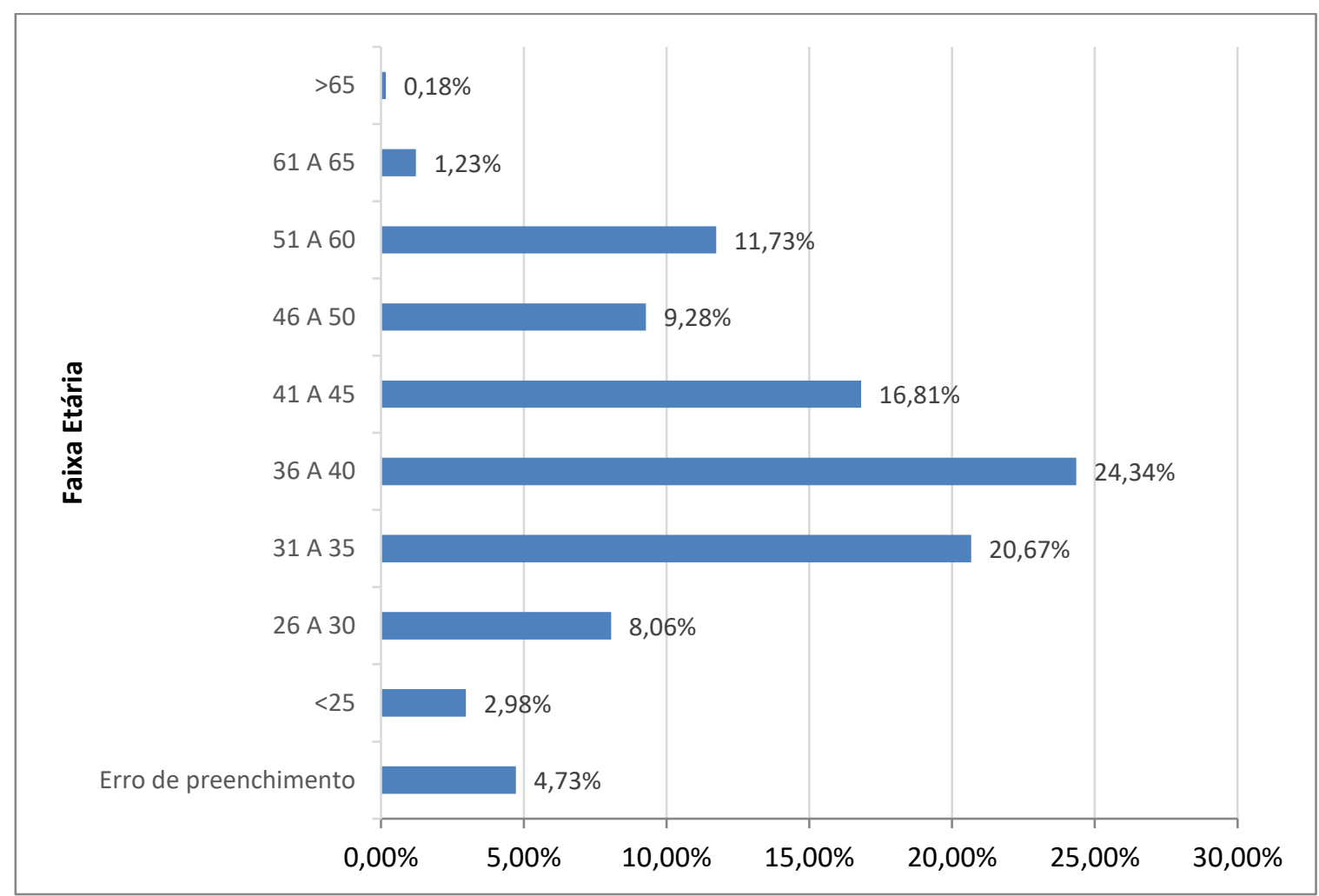

Fonte: Pesquisa realizada on-line com o envio pelo COREN -SP para verificar o conhecimento dos enfermeiros paulistas sobre o uso do CIAP, São Paulo, 2020. (Apêndice A).

Observa-se uma concentração maior de formandos a partir do ano 2001, com acentuação nos anos de 2006 a 2010.

Há um crescimento significativo de alunos que cursaram Universidades Privadas entre 2006 e 2010.

Dos enfermeiros respondentes, $76,88 \%$ haviam cursado uma Universidade Privada e 23, $12 \%$ uma Universidade Pública. 
Gráfico 2 - Distribuição dos enfermeiros quanto ao ano de conclusão da graduação e tipo de Universidade

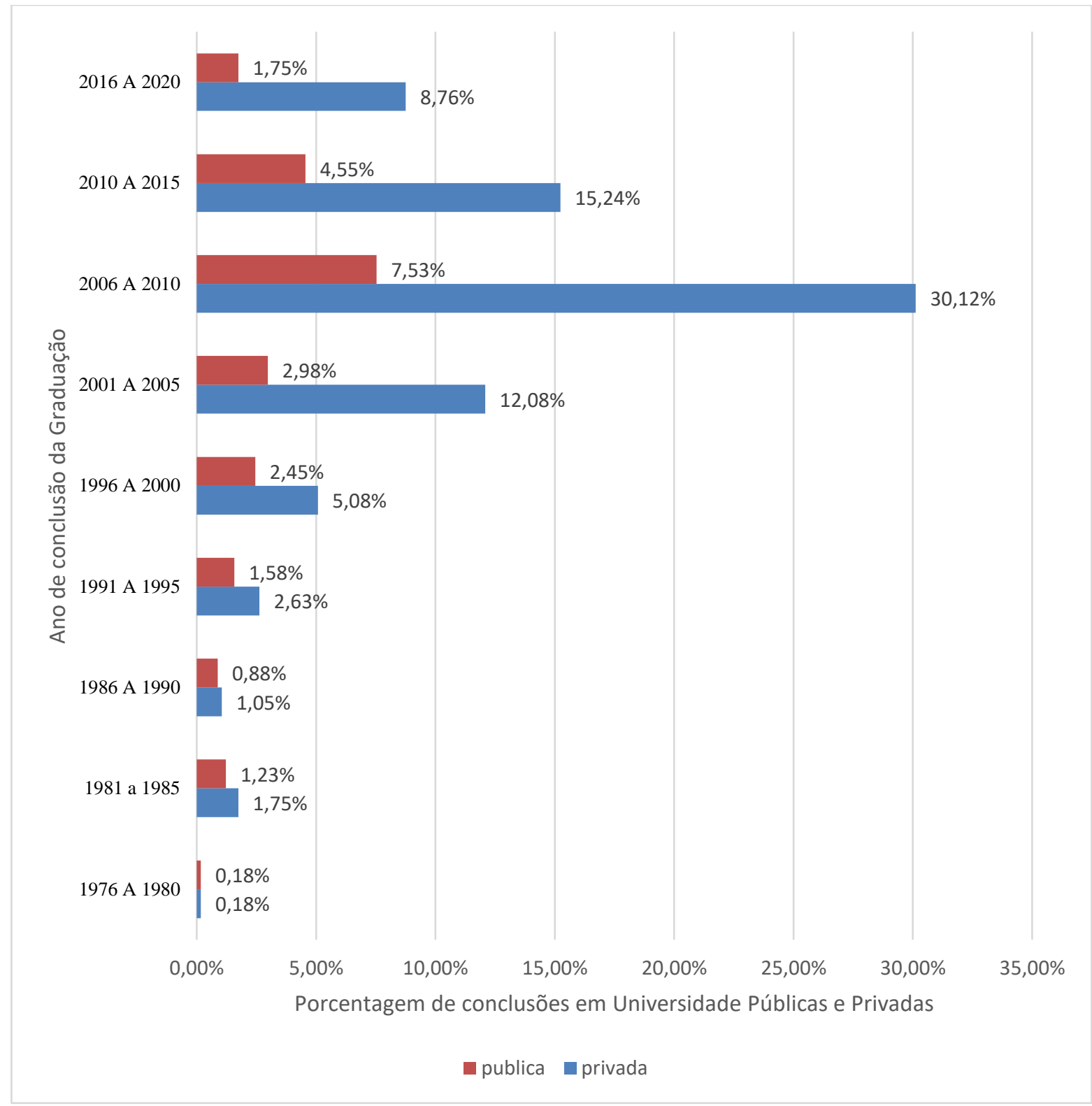

Fonte: Pesquisa realizada on-line com o envio pelo COREN -SP para verificar o conhecimento dos enfermeiros paulistas sobre o uso do CIAP, São Paulo, 2020. (Apêndice A).

Após um estudo para construir um panorama dos cursos de Graduação em Enfermagem no Brasil, que aconteceu no período 2001 a 2011, observou-se mediante os dados do Censo da Educação Superior, um crescimento no número de cursos de $393 \%$ nas instituições privadas e de $122 \%$ em relação ao número de cursos públicos ${ }^{(34)}$.

Este aumento é uma consequência do aumento no número de cursos/vagas em instituições públicas e privadas e da ampliação do acesso populacional à educação superior no país. A privatização do ensino de graduação em enfermagem é uma marca da década de $2000^{(34)}$ 
Em um outro estudo, que avaliou o aumento dos cursos de graduação de enfermagem no Brasil, foi identificado como determinantes o aumento da oferta de trabalho após o Sistema Único de Saúde (SUS) e do Programa de Saúde da Família (PSF), mudanças na Lei de Diretrizes e Bases da Educação, a privatização do ensino com a autonomia dada às universidades e a flexibilização dos currículos $^{(35)}$.

Dos respondentes $85,5 \%$ haviam realizado um curso ou mais de especialização, 59,42\% realizaram o curso em Universidades Privadas e 40,58\% em Universidades Públicas.

Obtiveram título de mestrado $11,8 \%$ e $2,8 \%$ de doutorado, o que vem de encontro a um estudo realizado em 2013 no Estado de São Paulo pela FIOCRUZ/COFEN que demonstra uma inserção em cursos de Especialização de 73,2\%, Mestrado 14,8\% e Doutorado 5,9\%.

Cursos de mestrado e doutorado em enfermagem, estão em constante expansão, no entanto os números de profissionais com essa formação podem ser considerados baixos, por diversos motivos, como a necessidade de inserção rápida no mercado de trabalho, dificuldades na obtenção de bolsas de estudo e a desvalorização da ciência no país ${ }^{(36)}$.

Gráfico 3 - Distribuição dos enfermeiros por ano de conclusão da Pós Graduação e tipo de Universidade 


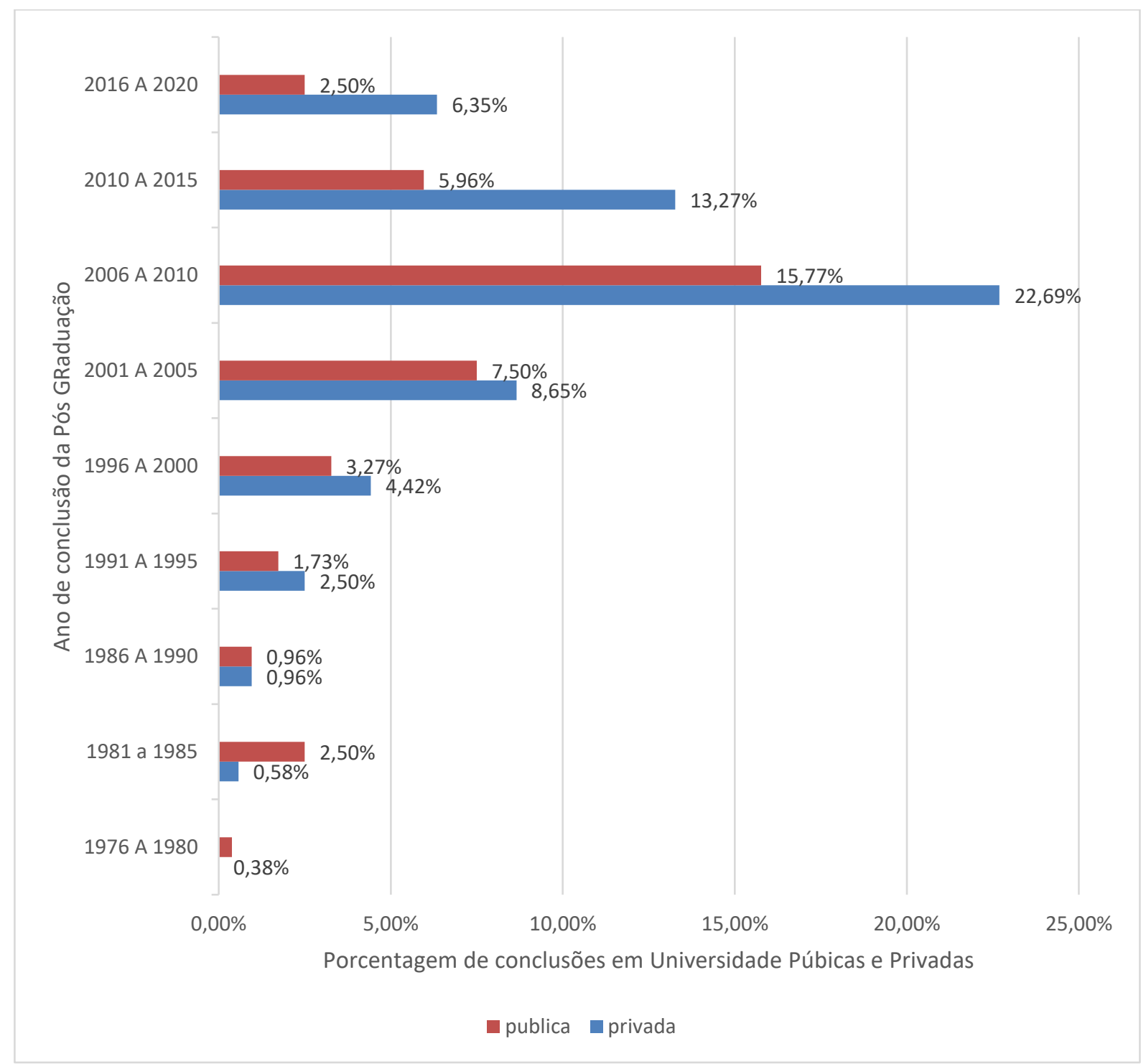

Fonte: Pesquisa realizada on-line com o envio pelo COREN -SP para verificar o conhecimento dos enfermeiros paulistas sobre o uso do CIAP, São Paulo, 2020. (Apêndice A).

\subsection{ANÁLISE DO CONHECIMENTO E USO DA CIAP}

$\mathrm{Na}$ segunda parte do questionário foram realizadas perguntas fechadas buscando explorar o entendimento dos enfermeiros quanto ao conhecimento, uso e treinamento para a CIAP.

Quando perguntado aos enfermeiros se eles conheciam e utilizavam a CIAP, 87,2\% disseram que sim e 78,2\% diziam utilizar a CIAP.

Dentre os profissionais que utilizavam a CIAP foi possível perceber que a maioria utiliza a CIAP a menos de seis anos, conforme distribuição do gráfico abaixo. 
Gráfico 4 - Distribuição quanto ao tempo de uso da CIAP

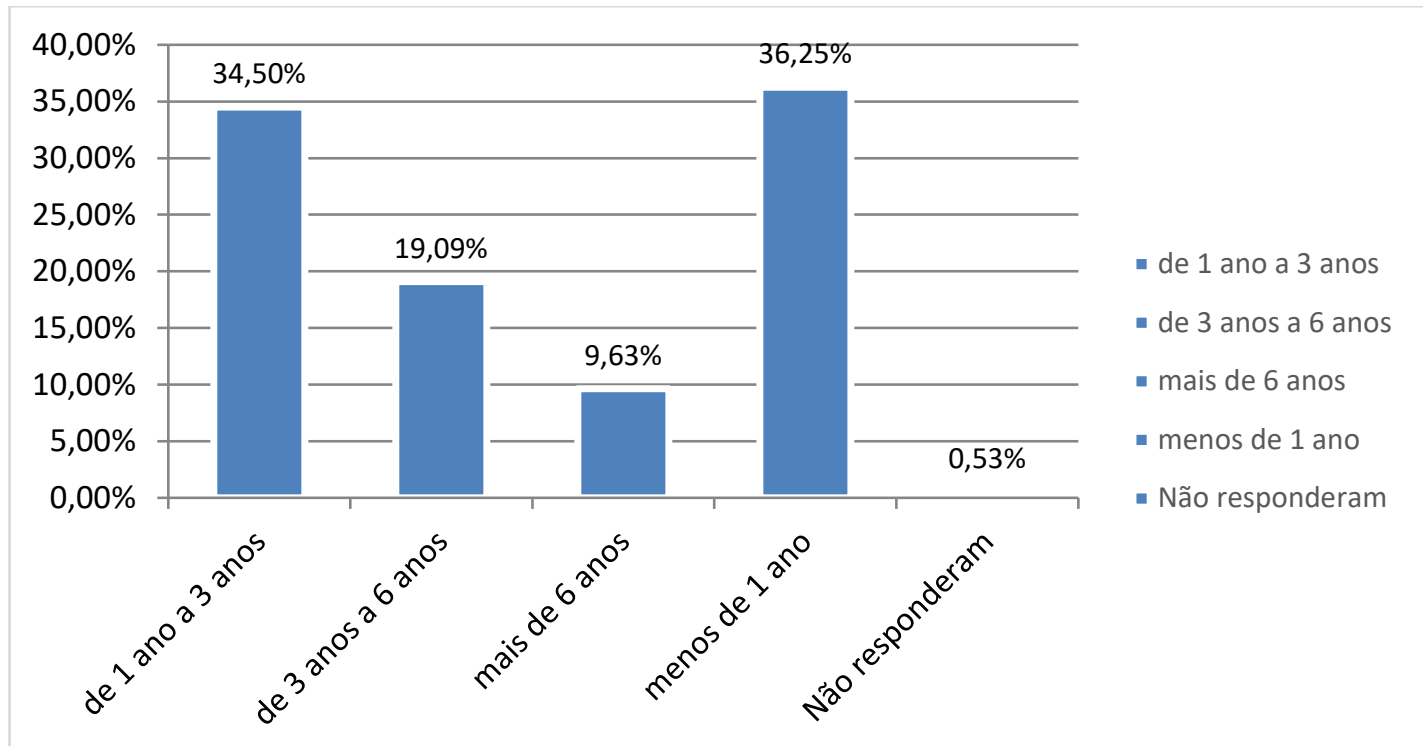

Fonte: Pesquisa realizada on-line com o envio pelo COREN -SP para verificar o conhecimento dos enfermeiros paulistas sobre o uso do CIAP, São Paulo,2020. (Apêndice A).

A obrigatoriedade de os profissionais classificarem seus atendimentos com a CIAP e preencherem a Ficha de Produção Individual com os dados obtidos nos atendimentos se deu pelo Ministério da Saúde a partir de 2013.

Porém quando questionados se hoje utilizam a CIAP na Ficha de Produção, 70,6\% afirmam que sim e $29,4 \%$ dizem não utilizar.

Quanto aos momentos em que os enfermeiros utilizavam a CIAP a maioria respondeu que a utilizava para classificar o Motivo de Consulta. 
Gráfico 5 - Distribuição quanto aos momentos em que os Enfermeiros utilizavam a CIAP

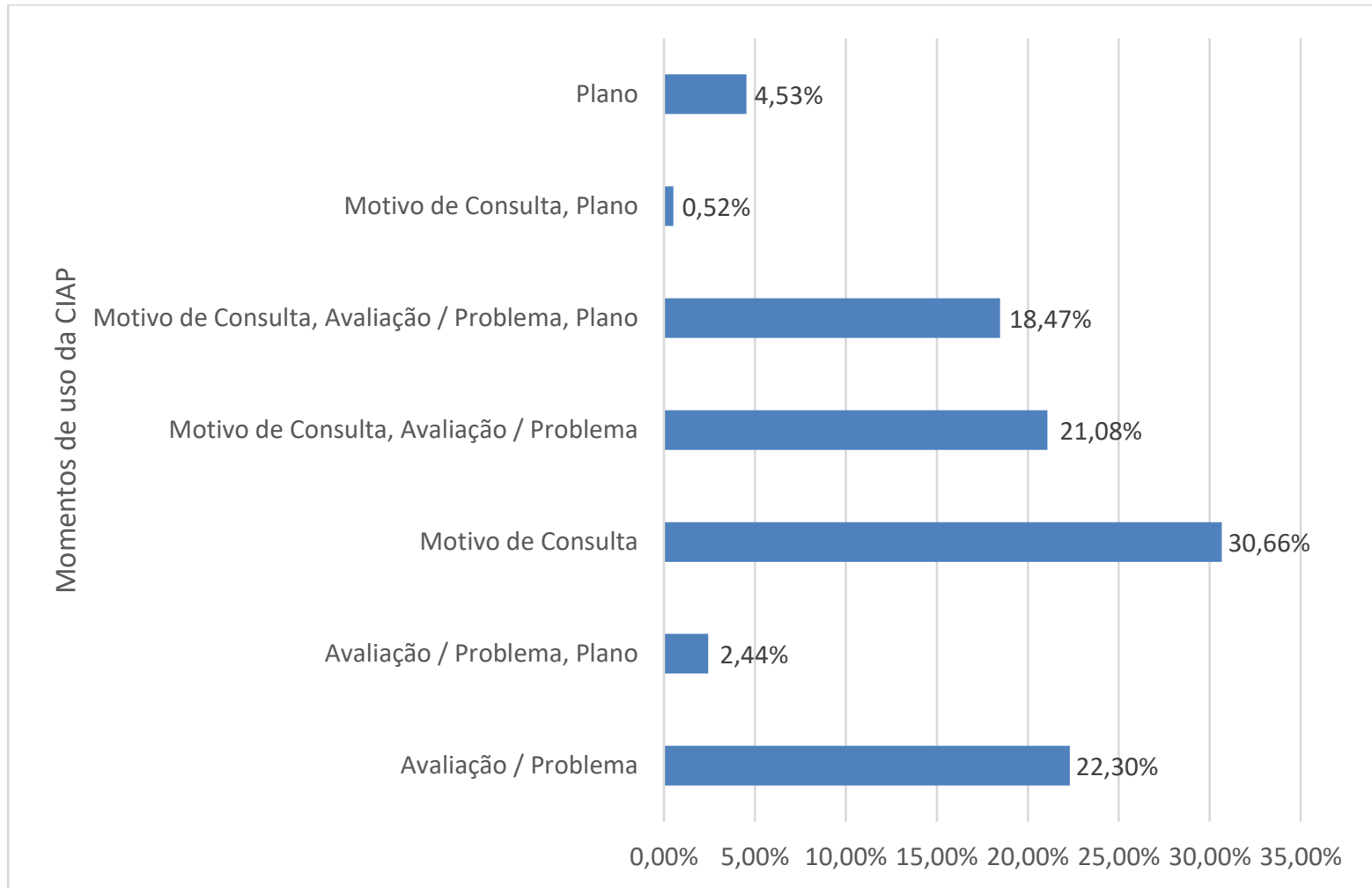

Fonte: Pesquisa realizada on-line com o envio pelo COREN -SP para verificar o conhecimento dos enfermeiros paulistas sobre o uso do CIAP, São Paulo, 2020. (Apêndice A).

O motivo de consulta é a razão que leva o indivíduo a buscar um serviço de saúde e é a partir dele que o profissional desenvolve um raciocínio clínico em busca do problema e de ações a serem destinadas para a pessoa $^{(4)}$

Foi a partir do desenvolvimento da Classificação de Motivos de Consulta que se percebeu que era possível e importante codificar os outros momentos da consulta - o problema detectado e o processo de cuidado, que englobam os procedimentos e condutas adotadas ${ }^{(37)}$.

Em uma pesquisa realizada em Portugal com base nos atendimentos realizados por dois médicos que eram orientadores do internato da Medicina de Família e Comunidade, em 2014, onde se observava as anotações nos campos do SOAP, entendendo o uso obrigatório da CIAP em cada consulta, mostrou que os profissionais classificavam no Subjetivo 98,7\%, no Objetivo 66,0\%, na Avaliação 97,8\% e no Plano 96,5\% das consultas ${ }^{(38)}$.

Outra pesquisa realizada para caracterizar a utilização mundial da CIAP, em 52 países respondentes, apenas 5\% diz utilizar a CIAP para classificar todos os momentos da consulta, o mais habitual é a utilização no Motivo de Consulta ${ }^{(39)}$.

Observar os dados obtidos através das classificações realizadas nos momentos dos atendimentos pode colaborar para a Gestão da Clínica. 
Quando analisado o motivo de consulta e a avaliação dos atendimentos realizados, é possível traçar um perfil dos frequentadores, ou seja, determinar os motivos que levam as pessoas procuram aquele serviço de saúde, proporcionando um ajuste de agenda, capacitação dos profissionais, e necessidades especificas, como atividades coletivas.

Outro dado que pode ser avaliado é a relação entre o motivo de consulta e a avaliação realizada pelos profissionais, isto pode mostrar qual a possibilidade de por exemplo uma pessoa que vem ao serviço se queixando de tosse ter uma pneumonia.

Para a coordenação do cuidado, que acontece em uma equipe transdisciplinar a linguagem única é um facilitador para a comunicação entre os profissionais.

Quando questionado se os enfermeiros haviam sido treinados para o uso da CIAP, observou-se que $80,1 \%$ não haviam recebido treinamento, vale ressaltar que 70,6\% dos enfermeiros disseram estar utilizando a CIAP para o preenchimento da Ficha de Produção Individual exigida pelo Ministério da Saúde, contrariando então uma das recomendações do COREN-SP, no Parecer COREN_SP 010/2015 ${ }^{(10)}$.

Quando interrogados sobre a necessidade de um treinamento para a utilização da CIAP, 93,6\% entendem ser necessário.

Em uma pesquisa avaliou-se a confiabilidade de estudantes de medicina para utilizar a CIAP codificando os atendimentos no motivo de consulta e na avaliação, foi verificado que após treinamentos havia uma confiabilidade de moderada a substancial (AC1 0,805; IC 95\% 0,767-0,843) e validade substancial (AC1 0,864; IC 95\% 0,833-0,891) ${ }^{(40)}$.

E por fim foi indagada de que forma os enfermeiros gostariam de ser treinados e 39,32\% responderam que gostariam de receber o treinamento de forma presencial e 44,34\% por aulas on-line.

Em um trabalho de revisão sistemática realizado em 2014, que teve como tema a Capacitação em Saúde na Educação a Distância $(\mathrm{EaD})$, percebeu-se a utilização de diferentes métodos para a capacitação em Educação a Distância, demonstrando a efetividade da modalidade, o que torna a formação e a informação em saúde favorável aos profissionais, portanto constituindo um recurso que favorece o processo de ensino-aprendizagem, no qual se desenvolvem estratégias de acesso a ambientes virtuais de aprendizagem que permite capacitação continuada em saúde possibilitando e potencializando a aprendizagem dos profissionais que atuam na área da saúde ${ }^{(41)}$. 
Gráfico 6 - Distribuição da preferência de modelo de treinamento no CIAP

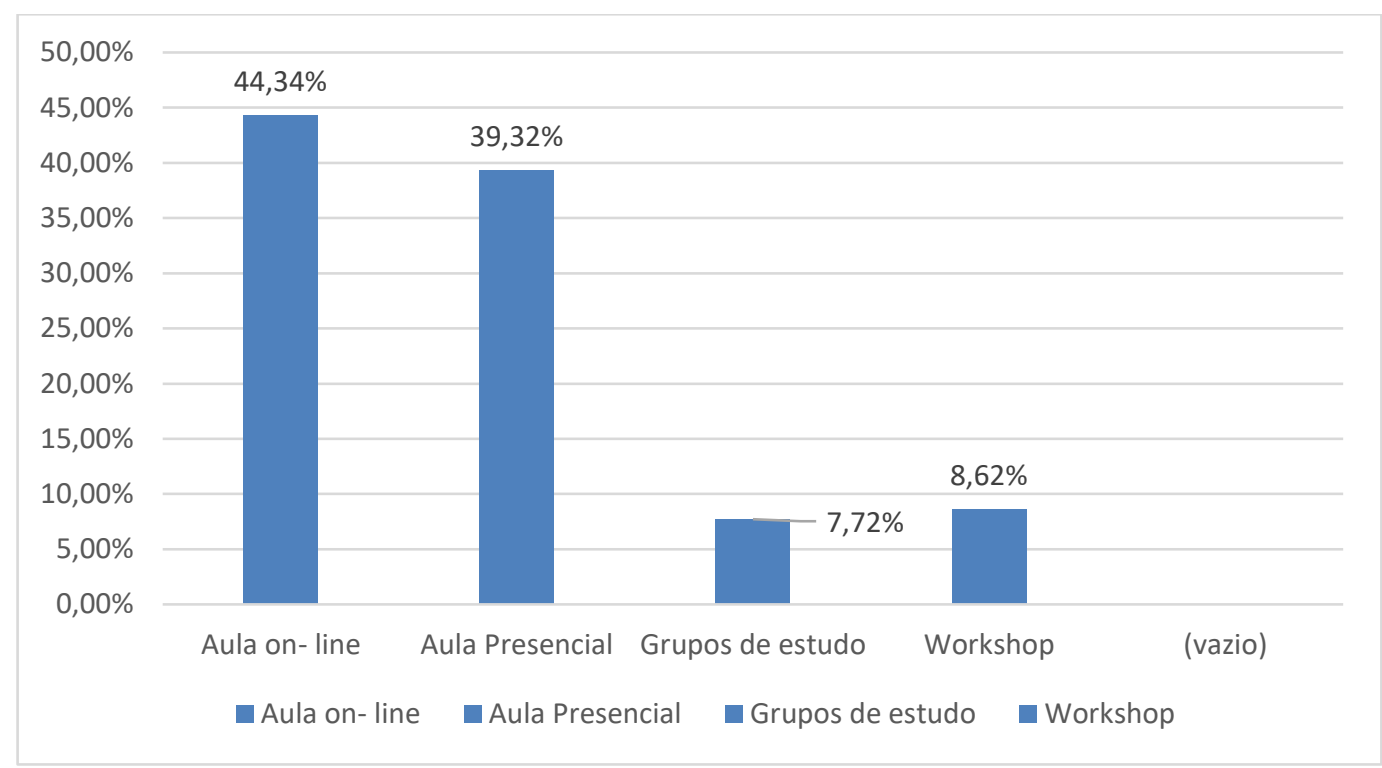

Fonte: Pesquisa realizada on-line com o envio pelo COREN -SP para verificar o conhecimento dos enfermeiros paulistas sobre o uso do CIAP, São Paulo, 2020. (Apêndice A).

\subsection{PRODUTO DESENVOLVIDO A PARTIR DA PESQUISA - LINHAS GERAIS PARA O DESENVOLVIMENTO DE UM CURSO EAD SOBRE CIAP PARA ENFERMEIROS.}

A partir dos resultados encontrados nessa pesquisa e diante da necessidade de se contar com profissionais capacitados para melhores resultados no cuidado das pessoas, delineou-se um planejamento de um Curso EAD para enfermeiros com interesse em se instrumentalizar para utilizar a CIAP de forma adequada e podendo usar as informações geradas a partir da clínica para a gestão dos processos de trabalho.

As aulas serão oferecidas por EAD e estarão distribuídas em 3 módulos, divididos por tópicos centrais, a saber:

- Evolução histórica da CIAP;

- Estrutura da CIAP e forma de utilização;

- Casos clínicos para o desenvolvimento da prática; que são essenciais para a compreensão do tema proposto visando que ao fim dessa capacitação os profissionais consigam realizar as classificações em CIAP de forma adequada e utilizem estes dados para a Gestão da sua Clínica.

Objetivo: oferecer ao aluno um conteúdo que lhe proporcione conhecer a evolução histórica da CIAP, entender o porquê de utilizar a classificação, compreender a estrutura, 
conhecer e desenvolver a habilidade de manusear o livro e seu sumário, reconhecer os momentos que é possível classificar (SOAP), avaliar as relações entre os momentos avaliados e como utilizar os dados para a gestão da clínica (ANEXO E). 
8 CONCLUSÃO 


\section{CONCLUSÃo}

O principal motivador para esta pesquisa foi elucidar o conhecimento dos Enfermeiros do Estado de São Paulo quanto a CIAP.

Os resultados trouxeram contribuições para esta elucidação, suas potencialidades e limitações, além de fortalecer reflexões sobre a proposta de treinamentos.

Observa-se que um número expressivo de enfermeiros está utilizando a CIAP, porém sem um conhecimento aprofundado da sua aplicabilidade e estrutura.

Os dados encontrados no presente estudo, foram semelhantes a outros estudos, quanto ao perfil dos enfermeiros.

A CIAP é uma importante codificação para a APS é focada na pessoa e pode ser utilizada para classificar o problema de saúde em vários momentos da consulta quando utilizado o registro em SOAP colaborando com a padronização dos dados coletados, estruturando o atendimento clínico, facilitando a coleta de dados para a pesquisa e gestão da clínica.

Este registro permite avaliar os episódios de cuidado dos clientes ao longo da sua jornada (vida), garantindo a longitudinalidade do cuidado, pesquisas e a gestão da clínica.

Esse é o primeiro estudo que busca elucidar o conhecimento da CIAP pelos enfermeiros do Estado de São Paulo que atuam na APS. É necessário que novos estudos se aprofundem no seu uso, avaliando a acurácia dos dados e sua aplicabilidade para pesquisas e gestão.

Acredita-se que após treinamento os profissionais terão potencial para realizar codificações com um grau de acurácia confiável, podendo então esses dados serem utilizados para pesquisas e gestão da clínica, proporcionando aos profissionais de saúde subsídios para prestar um cuidado baseado na integralidade e singularidade, influenciar a adoção de novas práticas em saúde, embasar ações, fortalecer políticas públicas e fomentar novas discussões acadêmicas. 
REFERÊNCIAS 


\section{REFERÊNCIAS}

1 World Health Organization. Primary health care: report of the International Conference on Primary Health Care, Alma-Ata, USSR [Internet]. Geneve: WHO; 1978 [cited 2020 Jan 20]. Available from: https://www.who.int/publications/almaata_declaration_en.pdf?ua=1

2 Brasil. Ministério da Saúde. Política nacional de atenção básica [Internet]. Brasília: Ministério da Saúde, 2012 [cited 2019 Jan 20]. Available from:

http://189.28.128.100/dab/docs/publicacoes/geral/pnab.pdf

3 Starfield B. Is primary care essential? Lancet [Internet]. 1994 [cited 2020 Jan 20];344(8930):1129-33. Available from: https://www.sciencedirect.com/science/article/abs/pii/S0140673694906343. DOI: https://doi.org/10.1016/S0140-6736(94)90634-3.

4 Santos KPB, Ribeiro MTAM. Motivos de consulta mais comuns das pessoas atendidas por uma equipe de saúde da família em Fortaleza - CE. Rev Bras Med Fam Comunidade [Internet]. 2015 [cited 2020 Jan 20];10(37):1-11. Disponível em:

https://rbmfc.org.br/rbmfc/article/view/831. DOI: https://doi.org/10.5712/rbmfc10(37)831.

5 Starfield B. Atenção primária: equilíbrio entre necessidades de saúde, serviços e tecnologia [Internet]. Brasília: UNESCO; 2002 [cited 2020 Jan 20]. Available from:

https://www.nescon.medicina.ufmg.br/biblioteca/imagem/0253.pdf

6 Gusso GDF. Diagnóstico de demanda em Florianópolis utilizando a Classificação Internacional de Atenção Primária: $2^{\mathrm{a}}$ ed. (CIAP-2) [dissertação] [Internet]. São Paulo: Faculdade de Medicina, Universidade de São Paulo; 2009 [cited Jan 20]. Available from: https://www.teses.usp.br/teses/disponiveis/5/5159/tde-08032010164025/publico/GustavoGusso.pdf

7 Lebrão ML. Classificação internacional de motivos de consulta para assistênciaprimária: teste em algumas áreas brasileiras. Rev Saude Publica [Internet]. 1985 [cited 2020 Jan 20];19(1):69-78. Available from: https://www.scielo.br/pdf/rsp/v19n1/08.pdf. DOI; https://doi.org/10.1590/S0034-89101985000100008.

8 Brasil. Ministério da Saúde, Universidade Federal de Santa Catarina. e-SUS atenção básica: sistema com coleta de dados simplificada - CDS: manual do digitador [Internet]. Brasília: Ministério da Saúde, 2013 [cited 2019 Jan 20]. Available from: http://189.28.128.100/dab/docs/portaldab/documentos/manual_digitador.pdf

9 Landsberg GAP, Savassi LCM, Sousa AB, Freitas JMR, Nascimento JLS, Azagra R. Análise de demanda em Medicina de Família no Brasil utilizando a Classificação Internacional de Atenção Primária. Cien Saude Colet [Internet]. 2012 [cited 2020 Jan 20];17(11):1-8. Available from: https://www.scielo.br/pdf/csc/v17n11/v17n11a18.pdf. DOI; https://doi.org/10.1590/S1413-81232012001100019.

10 Conselho Regional de Enfermagem (SP). Parecer COREN-SP 010/2015 - CT Processo $\mathrm{n}^{\circ}$ 3851/2015. Uso da Classificação Internacional da Atenção Primária (CIAP) por enfermeiros que atuam em Atenção Primária e Estratégia Saúde da Família [Internet]. São Paulo: Coren; 
2015 [cited 2019 Jan 20]. Available from: https://portal.corensp.gov.br/sites/default/files/010.2015CIAP-2_Aprovada\%20na\%20ROP.pdf

11 Mata LRF, Souza CC, Chianca TCM, Carvalho EC. Elaboração de diagnósticos e intervenções à luz de diferentes sistemas de classificações de enfermagem. Rev Esc Enferm USP [Internet]. 2012 [cited 2020 Jan 20];46(6):1512-8. Available from: https://www.scielo.br/pdf/rsp/v19n1/08.pdf. DOI; https://doi.org/10.1590/S003489101985000100008.

12 Comitê Internacional de Classificação da WONCA. Classificação Internacional de Atenção Primária (CIAP2) [Internet]. $2^{\mathrm{a}}$ ed. Florianópolis: Sociedade Brasileira de Medicina de Família e Comunidade; 2009 [cited 2020 Jan 20]. Available from:

http://www.sbmfc.org.br/wp-

content/uploads/media/file/CIAP\%202/CIAP\%20Brasil_atualizado.pdf

13 Mendes EV. As redes de atenção à saúde [Internet]. Brasília: Organização Pan-Americana da Saúde; 2011 [cited 2019 Jan 20]. Available from:

https://www.paho.org/bra/index.php?option=com_docman\&view=download\&category_slug= $\underline{\text { servicos-saude-095\&alias }=1402 \text {-as-redes-atencao-a-saude- } 2 \text { a-edicao- } 2 \& \text { Itemid }=965}$

14 Gusso GDF, Poli Neto P. Gestão da clínica. In: Gusso GDF, Lopes JMC, editores. Tratado de medicina de família e comunidade. Porto Alegre: Artmed; 2012. p. 159-65.

15 Casajuana J, Bellón J. La gestión de la consulta en atención primaria. In: Martin Zurro A, Cano-Pérez J, editores. Atención primaria: conceptos, organización y práctica clínica. $5^{\mathrm{a}}$ ed. Madrid: Elsevier; 2003. p. 84-109.

16 White KL, Williams TF, Greenberg BG. The ecology of medical care. N Engl J Med [Internet]. 1961 [cited 2019 Jan 20];265:885-92. Available from: https://www.nejm.org/doi/pdf/10.1056/NEJM196111022651805. DOI: 10.1056/NEJM196111022651805.

17 Araújo LN, Figueira MD. Gestão da clínica. In: Valladão Júnior JBR, Gusso G, Olmos RD, editores. Medicina de família e comunidade. Rio de Janeiro: Atheneu; 2017. p. 3-22.

18 Hart JT. The inverse care law. Lancet [Internet]. 1971 [cited 2019 Jan 20];297(7696):40512. Available from: https://www.sciencedirect.com/science/article/pii/S014067367192410X. DOI: https://doi.org/10.1016/S0140-6736(71)92410-X.

19 Cunha EM, Giovanella L. Longitudinalidade/continuidade do cuidado: Identificando dimensões e variáveis para a avaliação da atenção primária no contex to do sistema público de saúde brasileiro. Cien Saude Colet [Internet]. 2011 [cited 2020 Jan 20];16 Supl 1:1029-42. Available from: https://www.scielo.br/pdf/csc/v16s1/a36v16s1.pdf. DOI: https://doi.org/10.1590/S1413-81232011000700036

20 Bousquat A, Giovanella L, Campos EMS, Almeida PF, Martins CL, Mota PHS, et al. Atenção primária à saúde e coordenação do cuidado nas regiões de saúde: perspectiva de gestores e usuários. Cien Saude Colet [Internet]. 2017 [cited 2019 Jan 20];22(4): 1141-54. Available from: https://www.scielo.br/pdf/csc/v22n4/1413-8123-csc-22-04-1141.pdf. DOI: https://doi.org/10.1590/1413-81232017224.28632016. 
21 Orozco Beltrán D, Pedrera Carbonell V, Gil Guillén V, Prieto Erades I, Ribera Montés MC, P. Martínez Cánovas. Gestión clínica de la consulta: Previsibilidad y contenido clínico (Estudio SyN-PC). Aten Primaria [Internet]. 2004 [cited 2019 Jan 20];33(2):69-77. Available from: https://www.elsevier.es/es-revista-atencion-primaria-27-articulo-gestion-clinicaconsulta-previsibilidad-contenido-13057254

22 Sociedad Española de Medicina de Familia y Comunitaria. Medidas concretas para la desburocratización de las consultas de Atención Primaria [Internet]. Barcelona: semFYC; 2008 [cited 2020 Jan 20]. Available from: https://www.semfyc.es/wpcontent/uploads/2016/04/2008.-DOCU-25-DESBRUROCRATIZACI\%C3\%93N.pdf

23 Brasil. Conselho Nacional de Secretários de Saúde. Atenção primária e promoção da saúde [Internet]. Brasília: CONASS; 2015 [cited 2019 Jan 20]. Available from: https://www.conass.org.br/biblioteca/pdf/atualizacao-2015/L03_ATENCAO-PRIMARIA-ASAUDE_jun2015.pdf

24 Minayo MCS. O desafio do conhecimento: pesquisa qualitativa em saúde. $13^{\text {a }}$ ed. São Paulo: Hucitec; 2013.

25 Polit DF, Beck CT, Hungler BP. Fundamentos de pesquisa em enfermagem. $5^{\text {a }}$ ed. Porto Alegre: Artmed; 2004.

26 Richardson RJ. Pesquisa social: métodos e técnicas. $3^{\text {a }}$ ed. rev. ampl. São Paulo: Atlas; 1999.

27 Trivinos ANS. Introdução à pesquisa em ciências sociais: a pesquisa qualitativa em educação. São Paulo: Atlas, 1987.

28 Governo do Estado de São Paulo. São Paulo: população do estado [Internet]. São Paulo: Fundação SEADE; 2018 [cited 2020 Jun 28]. Disponível em:

<http://www.bibliotecavirtual.sp.gov.br/temas/sao-paulo/sao-paulo-populacao-doestado.php>. Acesso em: 17 out. 2019.

29 São Paulo. Conselho Regional de Enfermagem. Enfermagem em números [Internet]. São Paulo: Coren; 2020 [cited 2020 Jun 28]. Available from: https://portal.corensp.gov.br/enfermagem-numeros-dados.php

30 Brasil. Conselho Federal de Enfermagem. Pesquisa perfil da enfermagem [Internet] Brasília: Cofen/Fiocruz; 2013 [cited 2019 Jan 20]. Available from: http://www.cofen.gov.br/perfilenfermagem/index.html\#: :text=A\%20pesquisa\%20traz\%20o \%20perfil,campo\%20da\%20Sa \% $3 \%$ BAde $\% 20$ no\%20Brasil.\&text $=\mathrm{A} \% 20$ pesquisa $\% 20$ foi $\%$ 20realizada\%20pela,da\%20profiss $\%$ C $3 \%$ A3o $\% 20 \mathrm{e} \% 20$ propor $\% 20$ mudan $\% \mathrm{C} 3 \% \mathrm{~A} 7 \mathrm{as}$.

31 Lino TR, Mayorga C. As mulheres como sujeitos da ciência: uma análise da participação das mulheres na Ciência Moderna. Saude Transform Social [Internet]. 2016 [cited 2019 Jan 20];7(3):96-107. Available from:

http://incubadora.periodicos.ufsc.br/index.php/saudeetransformacao/article/view/4239/4651

32 Barbosa ACS, Luiz FS, Friedrich DBC, Püschel VAA, Farah BF, Carbogim FC. Profile of nursing graduates: competencies and professional insertion. Rev Latinoam Enferm [Internet]. 
2019 [cited 2019 Jan 20];27:e3205. Available from: https://www.scielo.br/pdf/rlae/v27/01041169-rlae-27-e3205.pdf. DOI: http://dx.doi.org/10.1590/1518-8345.3222.3205.

33 Miguel B, Durães M. Gestão do envelhecimento no trabalho de médicos e enfermeiros: estratégias para o prolongamento da sua vida ativa [dissertação] [Internet]. Porto: Faculdade de Educação e Psicologia, Universidade Católica Portuguesa; 2019 [cited 2019 Oct 19]. Available from:

https://repositorio.ucp.pt/bitstream/10400.14/29939/1/Disserta\%C3\%A7\%C3\%A3o_Bruno\% 20Dur\%C3\%A3es.pdf

34 Teixeira E, Fernandes JD, Andrade AC, Silva KL, Rocha MEMO, Lima RJO. Panorama dos cursos de graduação em enfermagem no Brasil na década das diretrizes curriculares nacionais. Rev Bras Enferm [Internet]. 2013 [cited 2020 Jan 20];66(N. esp.):102-10. Available from: https://www.scielo.br/pdf/reben/v66nspe/v66nspea14.pdf. DOI: http://dx.doi.org/10.1590/S0034-71672013000700014.

35 Silva EM, Baragatti DY, Figueira MCS, Lima RS, Silva TC. O aumento dos cursos de graduação em enfermagem no Brasil nos últimos 15 anos: determinações e sustentabilidade [Internet]. In: Anais do 61 ${ }^{\circ}$ Congresso Brasileiro de Enfermagem; 2009 dez.7-10; Fortaleza. Fortaleza: ABEn; 2009 [cited 2020 Jan 20]. p. 2345-51. Available from: https://www.researchgate.net/publication/298215722_O_AUMENTO_DOS_CURSOS_DE GRADUACAO_EM_ENFERMAGEM_NO_BRASIL_NOS_ULTIMOS_15_ANOS

36 Carvalho SR. A decadência ideológica da burguesia e a desvalorização da produção científica nacional. Cad GPOSSHE [Internet]. 2020 [cited 2019 Jan 20];3(1):130-43. Available from: https://revistas.uece.br/index.php/CadernosdoGPOSSHE/article/view/2780. DOI: https://doi.org/10.33241/cadernosdogposshe.v3i1.2780.

37 Soler J, Okkes I, Wood M, Lamberts H. The coming of age of ICPC: celebrating the 21st birthday of the International Classification of Primary Care. Fam Pract [Internet]. 2008 [cited 2020 Jan 20];25(4):312-7. Available from:

https://academic.oup.com/fampra/article/25/4/312/604241. DOI: https://doi.org/10.1093/fampra/cmn028.

38 Santiago LM, Carvalho R, Botas P, Miranda P, Matias C, Simões AR, et al. A informação na consulta presencial em Medicina Geral e Familiar: classificações segundo a ICPC-2 e anotações livres para a memória futura no SOAP. Rev Bras Med Fam Comunidade [Internet]. $30^{\circ}$ de setembro de 2015 [cited 2020 Jan 20];10(36). Disponível em:

https://rbmfc.org.br/rbmfc/article/view/840. DOI: https://doi.org/10.5712/rbmfc10(36)840.

39 Basílio N, Ramos C, Figueira S, Pinto D. Worldwide usage of International Classification of Primary Care. Rev Bras Med Fam Comunidade [Internet]. 2016 [cited 2020 Jan 20];11(38):1-9. Available from: https://rbmfc.org.br/rbmfc/article/view/1225/769. DOI: https://doi.org/10.5712/rbmfc11(38)1225.

40 Fontenelle LF, Zamprogno AD, Rodrigues AFL, Sirtoli LC, Checon NJC, Vetis MS, et al. Reliability and validity of ICPC-2-R encoding by medical students. Rev Bras Med Fam Comunidade [Internet]. 2018 [cited 2020 Jan 20];13(40):1-6. Available from: https://rbmfc.org.br/rbmfc/article/view/1655/905. DOI: https://doi.org/10.5712/rbmfc13(40)1655. 
41 Quaglia I, Oliveira A, Velho APM. Capacitação em saúde na educação a distância (EaD): uma análise sistemática do conteúdo. Saúde e Pesq [Internet]. 2015 [cited 2020 Jan 20];8(N. esp.):103-12, 2015. Available from:

https://periodicos.unicesumar.edu.br/index.php/saudpesq/article/view/3767/2516 
APÊNDICES 


\section{APÊNDICE A - QUESTIONÁRIO}

Idade:

Instituição da graduação:

Pós-graduação:

Instituição da pós-graduação:

Instituição onde atua:
Sexo:

Ano de conclusão da graduação:

Ano de conclusão:

1- Você conhece a Classificação Internacional de Atenção Primária (CIAP)? Sim ( ) Não ( )

2- Você utiliza a Classificação Internacional de Atenção Primária (CIAP)? Sim ( ) Não ( )

3- Há quanto tempo você utiliza a Classificação Internacional de Atenção Primária (CIAP)?

menos de 6 meses ( )

6 meses a um ano ( )

Um ano a três anos ( )

Três anos a cinco anos ( )

Mais de 5 anos ( )

4- Você utiliza a Classificação Internacional de Atenção Primária (CIAP) para codificar o motivo de consulta?

Sim ( ) Não ( )

5- Você utiliza a Classificação Internacional de Atenção Primária (CIAP) para codificar a avaliação ou problema (diagnóstico)?

Sim ( ) Não ( )

6- Você utiliza a Classificação Internacional de Atenção Primária (CIAP) para codificar o plano?

Sim ( ) Não ( )

7- Você utiliza a Classificação Internacional de Atenção Primária (CIAP) no preenchimento da Ficha de Atendimento Individual (ficha de produção)?

Sim ( ) Não ( )

8- Você teve algum treinamento para o uso do Classificação Internacional de Atenção Primária (CIAP)?

Sim ( ) Não ( ) 
9- Você acha que seria necessário um treinamento?

Sim ( ) Não ( )

10- De que forma você gostaria que fosse realizado o seu treinamento para o uso da CIAP? Aula presencial

Aula on line

Grupo focal

Workshop

\section{Link da Pesquisa}

https://docs.google.com/forms/d/e/1FAIpQLSdhzCqJEtmRlGwqnmRiiszlZtC0xzVU1 $\underline{\text { Xs07JOXVsjDi-ZDQg/closedform }}$ 


\section{ANEXO A - CLASSIFICAÇÃO INTERNACIONAL DE ATENÇÃO PRIMÁRIA}

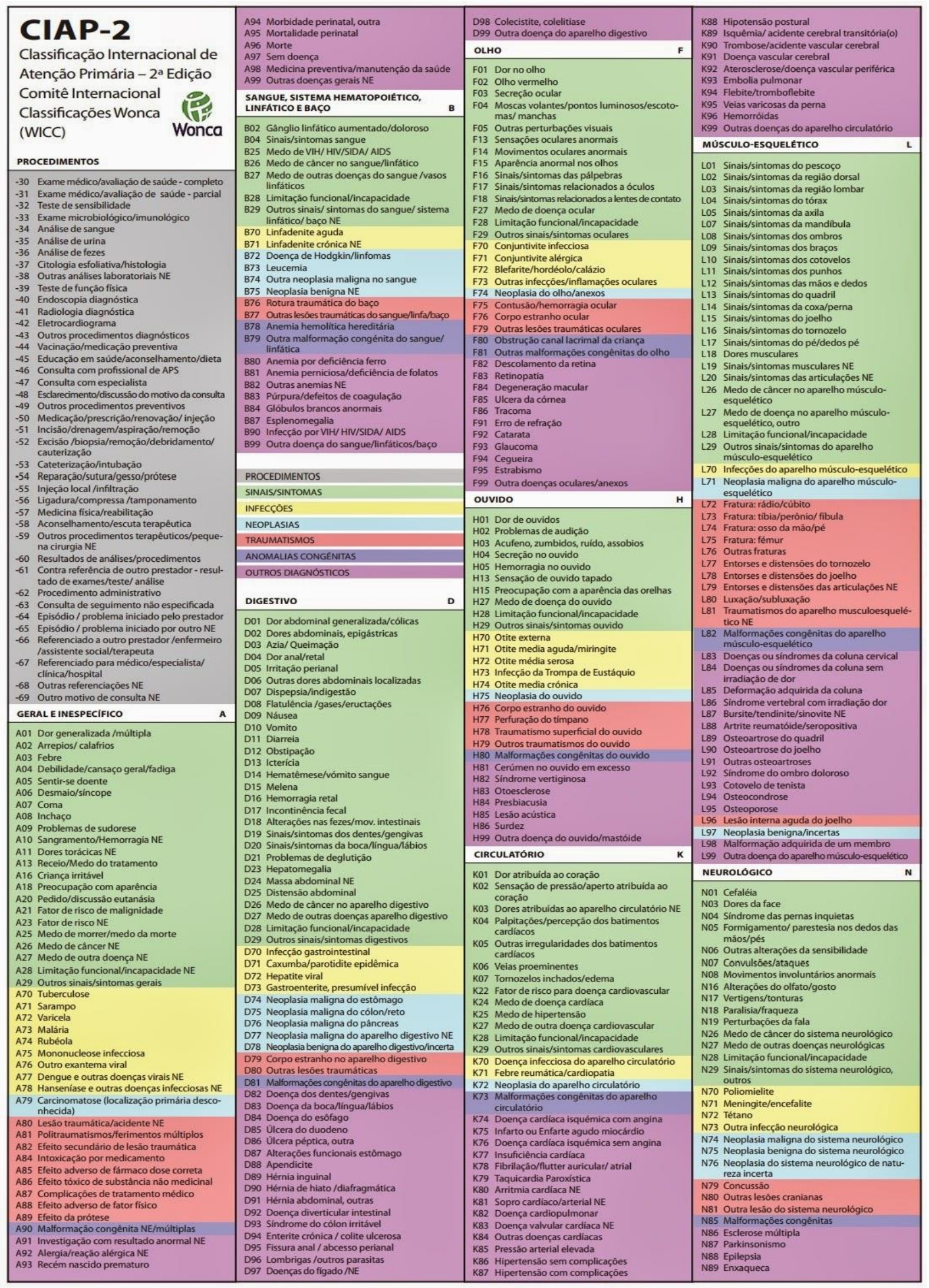




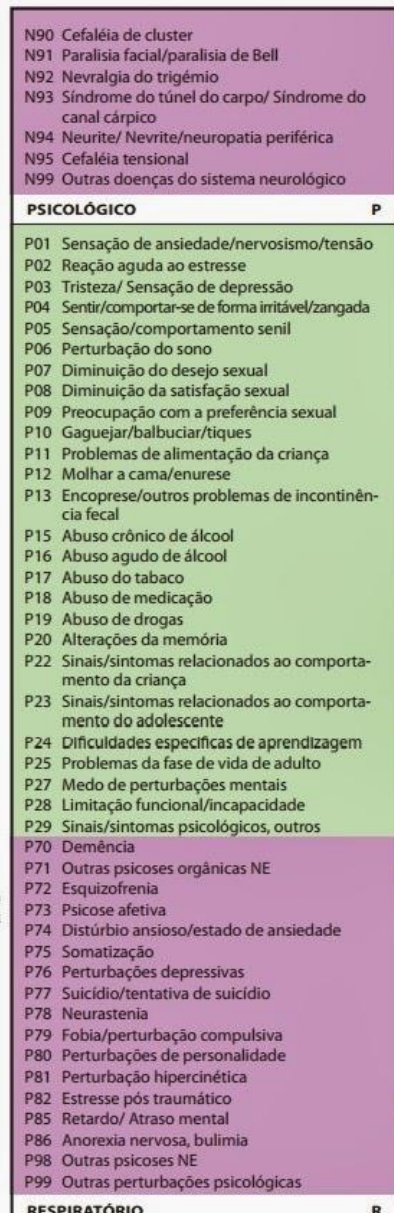

\section{RESPIRATÓRIO}

R01 Dor atribuida ao aparelho respiratório R02 Dificuldade respiratória, dispneia

R03 Respiraçáo ruidosa

R04 Outros problemas respiratórios

TO6 Hemorragia nasal/epistax

RO7 Espirro/congestão nasal

R09 Sinais/sintomas dos seios paranasais

R21 Sinais/sintomas da garganta

R23 Sinais/sintomas da voz

R24 Hemoptise

R25 Expectoraça/mucosidade anormal

R26 Medo de cảncer do aparelho respiratório

R27 Medo de outras doenças respiratórias

R29 Sinais/sintomas do aparelho respiratónio, outros

R71 Tosse convulsa/ pertussis

R72 Infecçăo estreptocócica da orofaringe

R73 Abcesso/furúnculo no nariz

R74 Infecçáo aguda do aparelho respiratório

775 Sinusite crónica/agu

R76 Amigdalite aguda

R77 Laringite/traqueite aguda

R78 Bronquite/bronquiolite aguda

R79 Bronquite crónica

R80 Gripe

R82 Pleurite/derrame pleural

ecçāo respiratória

R84 Neoplasia maligna dos brônquios/pulmáo

285 Outra neoplasia respiratória maligna

R86 Neoplasia benigna respiratór

R88 Outra lesáo respiratória

R88 Outra lesäo respiratória

R90 Hipertrofia das amigdalas/adenóides

R95 Doença pulmonar obstrutiva crónica

R96 Asma

R97 Rinite alérgica

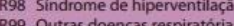

PELE

502 Dortsensido
503 Verrugas

504 Tumor/inchaço localizado

S05 Tumores/inchaços generalizados

S06 Erupção cutảnea localizada

507 Erupçáo cutánea generalizac

S08 Alteraçōes da cor da pele

S09 Infecçáo dos dedos das máos/pés

S10 Furúnculo/carbúnculo

S11 Infecçáo pós-traumática da pele

S12 Picada ou mordedura de inse
S13 Mordedura animal/humana

S14 Queimadura/escaldáo

S16. Corpo estranho na pele

S16 Traumatismo/contusảo
S17 Abrasăo/arranhăo/bolhas

S18 Laceraçäo/corte
519 Outra lesão cutáne

\$19 Outra lesão cutånea

S20 Calos/calosidades
$\$ 21$ Sinais/sintomas da textura da pel

$\$ 22$ Sinais/sintomas das unhas

\$23 Queda de cabelo/calvicie

S26 Medo de cáncer de pele

S26 Medo de cáncer de pele
S27 Medo de outra doença da pele

S28 Limitaçäo funcional/incapacidade

\$29 Sinais/sintomas da pele, outros

570 Herpes zoster

571 Herpes simples

S72 Escabiose/outras acariases
S73 Pediculose/outras infecçōes da pele

S74 Dermatofitose
S75 Moniliase oral/candidiase na pele

S75 Moniliase oral/candidiase
S76 Outras infecçóes da pele

S77 Neoplasias malignas da pele

S78 Lipoma
S79 Neoplasia cutánea benigna/incerta

S80 Ceratose/ Queratose solar/queimadura solar

581 Hemangioma/linfangioma

S82 Nevos/sinais da pele

S83 Lesōes da pele congènitas, outras

584 Impetigo

S85 Cisto pilonidal/fistula

S86 Dermatite seborreica
587 Dermatite/eczema atópico

S88 Dermatite de contato/alérgic

S89. Dermatite das fraldas

590 Pitiriase rosad

S91 Psoriase
S92 Doença das glândulas sudoriparas

593 Cisto sebáceo

595 Molusco contagioso

596 Acne

597 Ülcera crónica da pele

599 Outras doe

R ENDócrino/Metabólico

ENDOCRINO/M
ENUTRICIONAL

T01 Sede excessiva

T02 Apetite excessivo

T04 Problemas alimentares de lactente/criança

T05 Problemas alimentares do adulto

T07 Aumento de peso
T08 Perda de peso

T08 Perda de peso

T10 Atraso do crescimento

T26 Medo de câncer do sistema endócrino

T28 Limitaçáo funcional/incapacidade

T29 Sinais/sintomas endocrinológicos/metaboli-
Tolition

cos/nutricionais, out

T70 Infecçáo endócrina

T71 Neoplasia maligna da tiróide

172 Neoplasia benigna da tiróide

T73 Outra neoplasia endócrina NE
T78 Cisto do canal tiroglosso

T88 Cisto do canal tiroglosso
T80 Malformaçáo congénita endócrina/metabólica

T81 Bócio

T83 Excesso de pes

T85 Hipertiroidismo/tireotoxicose

T86 Hipotiroidismo/mixedema

T87 Hipoglicemia

T89 Diabetes insulino-dependente
T90 Diabetes nāo insulino-depend

T91 Deficiência vitamínica/nutricional

192 Go

T93 Alteraçăo no metabolismo dos lipidos

99 Outras doenças endocrinológica/metabóli-

URINÁRIO

U01 Disúria/micçáo doloros

U02 Micçăo frequente/urgência urinária/ polaciúria

U04 Incontinência urinária

U05 Outros problemas com a micção

U06 Hematuria
U07 Outros sinais/sintomas urinários U08 Retençảo urinária

U13 Sinais/sintomas da bexiga,
U14 Sinais/sintomas dos rins

U26 Medo de câncer no aparelho urinário

U27 Medo de outra doença urinária
U29 Sinais/sintomas aparelho urinário, outros U70 Pielonefrite
U71 Cistite/outra infecçāo urinária

U72 Uretrite

U75 Neoplasia maligna do rim

U76 Neoplasia benigna do rim

U77 Neoplasia maligna do aparelho urinário, outro

U78 Neoplasia benigna do aparelho urinário

U80 Lesōes traumáticas do aparellho urinário

U85 Malformaçáo congénita do aparelho urinário

U88 Glomerulonefrite/ sindrome nefrotica

U95 Cálculo urinário

U98 Análise de urina anormal $N$ E
U99 Outras doenças urinárias

GRAVIDEZ, PARTO $E$

PLANEJAMENTO FAMILIAR

W01 Questão sobre gravidez

W02 Medo de estar grávida

W05 Vómitos/náuseas durante a gravid

W10 Contraceppçáo pós-coital

W11 Contracepção oral

W12 Contracepção intra-uterina/ Dispositivo

Intrauterino/ DIU
W13 Esterilizaço

W13 Esterilizaçáo

W14 Contraceppáo/outros

W15 Infertilidade/subfertildade

W17 Hemorragia pos-parto

W19 Sinais/sintomas poss-parto

W21 Preocupaçäo com a imagem corpo

gravidez

W27 Medo de complicaçōes na gravidez

W28 Limitaçāo funcional/incapacidade

W29 Sinais/sintomas da gravidez,

W71 Infecçōes que complicam a gravide

W72 Neoplasia maligna relacionada com gravidez

W73 Neoplasia benigna/incerta relacionada com
a gravidez

a gravidez
W75 Lesóes traumäticas que complicam a gravidez

W76 Malformaçăo congénita que complica a gravidez

W80 Gravidez náo dépica

W81 Toxemia gravidica/ DHEG

W82 Aborto espontâneo

W83 Aborto provocado de alto risco

W84 Gravidez

W90 Parto sem complicaçōes de nascido vivo

w92 Parto senn complicaçoes de natimorto

w93 Parto com complicaçoes de nascido vivo

W94 Mastite puerperal
W95 Outros problemas da mama durante gravi-

W96 Outras complicaçōes do puerpério

W99 Outros problemas da gravidez/part

GENITAL FEMININO

X01 Dor genital

X02 Dores menstruais

X04 Relaçaco sexual dolorosa na mulher

X05 Menstruaçăo escassa/ausente

X06 Menstruaçâo excessiva

X07 Menstruaçāo irregular/frequente

X08 Hemorragia intermenstrual

X09 Sinais/sintomas pré-menstruais

X10 Desejo de alterar a data menstruaçáo

X11 Sinais/sintomas da menopausa/ climatério

X12 Hemorragia pós-menopausa

$\begin{array}{ll}\text { X13 } & \text { Hemorragia pós-co } \\ \text { X14 } & \text { Secreçăo vaginal } \\ \text { X15 } & \text { Sissions }\end{array}$

X15 Sinais/sintomas da vagina

$\times 17$ inissintomas da velva

X18 Dor na mama feminina

X19 Tumor ou nódulo na mama femini

X20 Sinais/sintomas do mamilo da mulher

X21 Sinais/sintomas da mama feminina, outros

X22 Preocupação com a aparência da mama

X23 Medo de doença de transmissão sexual

X25 Medo de disfunçáa sexua

X25 Medo de câncer genital

X27 Medo de outra doença genital/mama

X28 Limitaçāo funcional/incapacidade

X29 Sinais/sintomas do aparelho genital femini-

no, outra

X70 Sifilis feminina

X72 Candidiase genital feminina

X73 Tricomoniase genital feminin

X75 Neoplasia maligna do colo

X76 Neoplasia maligna da mama feminin

X77 Neoplasia maligna genital feminina, out

X78 Fibromioma uterino

X79 Neoplasia benigna da mama feminina/ fibroadenoma

X81 Neoplasia genital feminina, outra/NE X82 Lesāo traumática genital feminina X83 Malformaçôes congênitas genitais X84 Vaginite/vulvite NE
X85 Doença do colo NE X86 Esfregaço de Papanicolau/colpocitologia X87 Prolapso utero-vagin

X88 Doença fibrocística da mam

X89 Sindrome da tensão pré-menstru

X91 Condiloma acuminado

X92 Infecçāo por clamidia

X99 Doença genital feminina, outra

GENITAL MASCULINO

Y01 Dor no pênis

Y02 Dor no escroto/t

Y04 Sinais/sintomas do pênis, outros

Y05 Sinais/sintomas do escroto/testiculos, outros

Y07 Impotencine Ra prosta

as da funçáo sexual masculina

outros
Ynfertilidade/subfertildade masculina

Y13 Esterilizaçāo masculina

Y14 Planejamento familiar, outros

Y16 Sinais/sintomas da mama masculina
Y24 Medo de disfunçáo sexual masculina

Y25 Medo de doenç̧a sexualmente tran

Y26 Medo de câncer genital masculino

Medo de doença genital masculina, out

128 Limitaçăo funcional/incapacidad

Y29 Sinais/sintomas, outros

770 Sifflis masculina

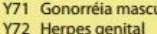

173 Prostatite/vesiculite seminal

Y74 Orquite/epididimite

Y75 Balanite/Balanopostite

76 Condiloma acuminado



Neoplasia maligna genital masculina, outr

Y80

Y81 Fimose/prepúcio redundante

182 Hipospádias

Y83 Testiculo não descido/Criptorquidia/TestiY84 Malformaçáa

genital congénita masculina,

Y85 Hipertrofia benigna da próstata/ hiperplasia Y86 Hidrocele

Y99 Doença genital masculina, outra

PROBLEMAS SOCIAIS

z

Z01 Pobreza/problemas econômicos Z02 Problemas relacionados a água/alimentaç Z03 Problemas de habitação/vizinhançă

Z04 Problema socio-cultural

Z05 Problemas com condiçōes de trabalho 206 Problemas de desemprego 207 Problemas relacionados com educaçáo segurança social

z09 Problema de ordem legal

Z10 Problema relacionado com sistema de saúde Z11 Problema relacionado com estar doente Z12 Problema de relacionamento com parceiro/ conjugal

Z13 Problema comportamental do parceiro/ Z14 Problema por doença do parceiro/companheiro Z16 Problemal cis Z18 Problema com criança doente Z19 Perda ou falecimento de crianca Z20 Problema de relacionamento com familiares Z21 Problema comportamental de familiar Z22 Problema por doença familiar

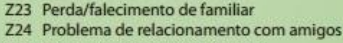
Z24 Problema de relacionamento Z27 Medo de problema social Z28 Limitaçăo funcional/incapacidad 


\section{ANEXO B - FICHA DE ATENDIMENTO INDIVIDUAL}

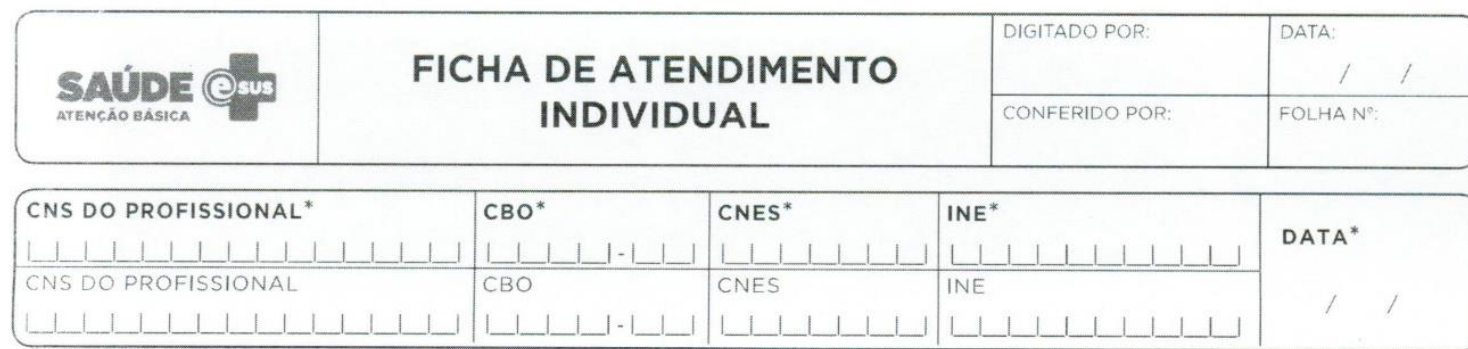

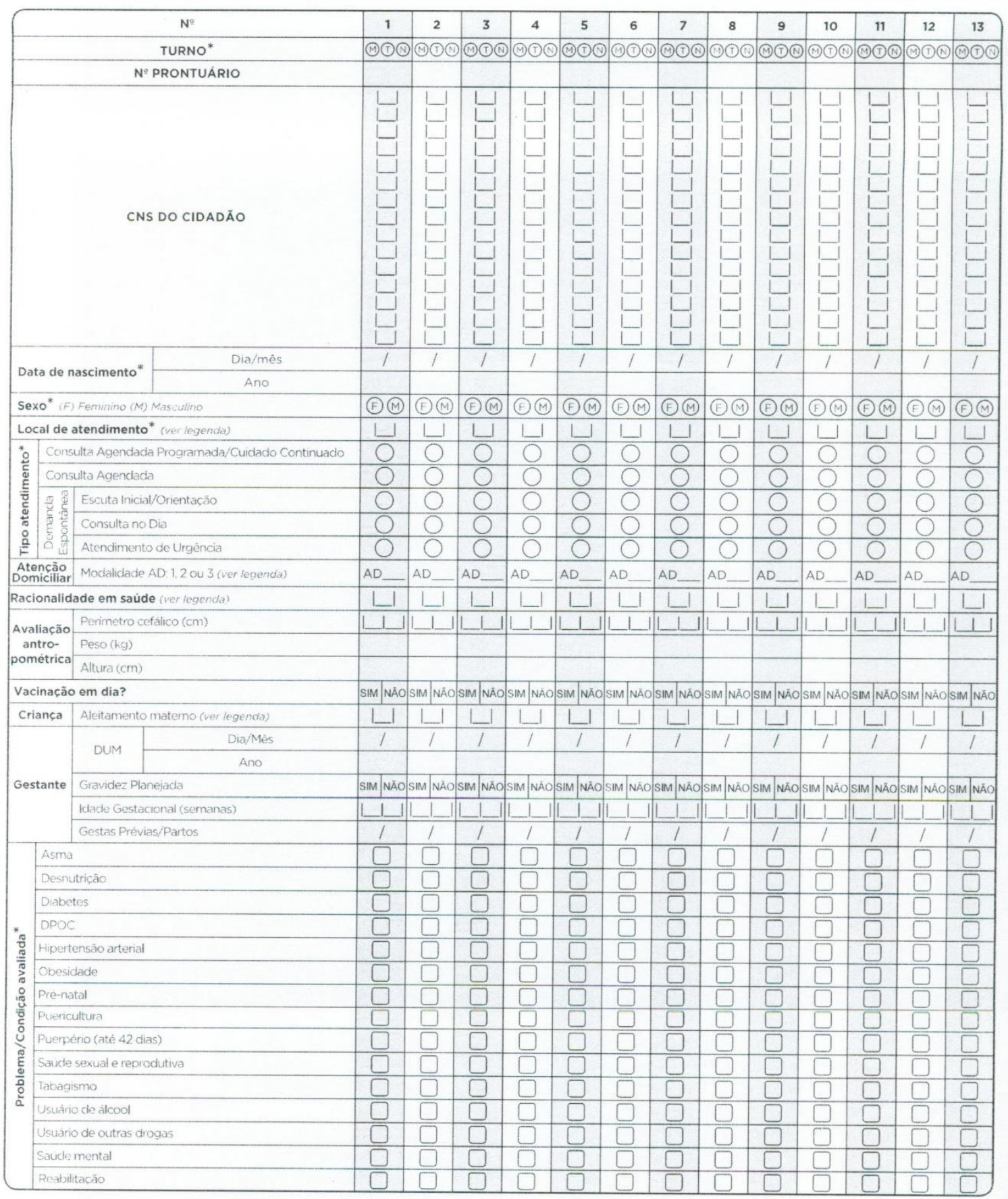




\begin{tabular}{|c|c|c|c|c|c|c|c|c|c|c|c|c|c|c|c|c|c|c|c|c|c|c|c|c|}
\hline \multicolumn{3}{|c|}{$\mathrm{N}^{\circ}$} & 1 & \multicolumn{2}{|r|}{2} & \multicolumn{2}{|c|}{3} & \multicolumn{2}{|l|}{4} & 5 & \multicolumn{2}{|c|}{6} & \multicolumn{2}{|c|}{7} & 8 & & 9 & 10 & & 11 & & 12 & 13 & \\
\hline & $\frac{n}{9}-$ & Tuberculose & $\square$ & & $\square$ & $\square$ & & $\square$ & & $\square$ & & ] & Q & & $\square$ & & $\square$ & {[} & & $\square$ & & $\square$ & $\square$ & \\
\hline & 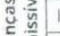 & Hanseniase & $\square$ & & $\square$ & 口 & & $\square$ & & $\square$ & & J & $\square$ & & $\square$ & & $\beth$ & C & ] & $\square$ & & $\square$ & $\square$ & \\
\hline & 列言! & Dengue & $\square$ & & $\square$ & 5 & ] & $\square$ & & Q & & ] & D & & $\square$ & & 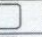 & 5 & 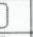 & $\square$ & & D & $\square$ & \\
\hline & $\frac{5}{4}$ & DST & $\square$ & & $\square$ & E & ] & D & & $\square$ & & ] & $\square$ & & $\square$ & & $\supseteq$ & & {[} & $\square$ & & $\square$ & $\square$ & \\
\hline & & Câncer do colo do útero & $\square$ & & $\square$ & ¿ & ] & $\square$ & & $\square$ & & ] & D & & D & & 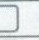 & & ] & $\square$ & & $\square$ & $\square$ & \\
\hline & & Cancer de mama & $\square$ & & $\square$ & E & ] & $\square$ & & $\square$ & & ] & D & & $\square$ & & $\supseteq$ & & ] & $\square$ & & $\square$ & $\square$ & \\
\hline & & Risco cardiovascular & $\square$ & & $\square$ & ᄃ & & $\square$ & & $\square$ & & ] & 口 & & $\square$ & & 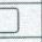 & C & ] & $\square$ & & $\square$ & $\square$ & \\
\hline & & CIAP-2 & & & & & & & & & & & & & & & & & & & & & & \\
\hline & 芒 & CIAP-2 & & & & & & & & & & & & & & & & & & & & & & \\
\hline & 今ે & $\mathrm{CID}-10$ & & & & & & & & & & & & & & & & & & & & & & \\
\hline & & CID-10 & & & & & & & & & & & & & & & & & & & & & & \\
\hline & Colest & terol total & & A 5 & A & $\mathrm{s}$ & & \begin{tabular}{l|l}
5 & 1 \\
\end{tabular} & & \begin{tabular}{l|l}
$S$ & $A$ \\
\end{tabular} & $\mathrm{~s}$ & A & 5 & & \begin{tabular}{l|l} 
& $A$ \\
\end{tabular} & & A & & A & S & & \begin{tabular}{l|l}
$S$ & A \\
\end{tabular} & s & \\
\hline & Creatir & inina & s & A & A & $\mathrm{s}$ & A & s & A & \begin{tabular}{l|l}
5 & $A$ \\
\end{tabular} & $\mathrm{~s}$ & A & $\mathrm{s}$ & A & $\mathrm{s}$ & s & A & $s$ & A & \begin{tabular}{l|l}
$s$ & $A$ \\
\end{tabular} & & \begin{tabular}{l|l} 
S & $A$ \\
\end{tabular} & $\mathrm{~s}$ & \\
\hline & EAS/E & QU & 5 & A & A & 5 & A & s & A & \begin{tabular}{l|l}
5 & $A$ \\
\end{tabular} & s & A & $\mathrm{s}$ & A & s & s & A & s & A & $s$ & & A & $\mathrm{s}$ & \\
\hline & Eletroc & cardiograma & 5 & A & $A$ & 5 & A & s & A & \begin{tabular}{l|l}
5 & A \\
\end{tabular} & 5 & A & $\mathrm{s}$ & A & 5 & $\mathrm{~s}$ & A & s & A & $s$ & & s & 5 & \\
\hline & Eletrof & forese de hemoglobina & 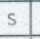 & A & A & s & A & 5 & A & \begin{tabular}{l|l|}
$S$ & $A$ \\
\end{tabular} & $\mathrm{~s}$ & A & s & A & s & $\underline{s}$ & A & $\mathrm{s}$ & A & $s$ s & & 5 & $\mathrm{~s}$ & \\
\hline & Espiro & metria & $\mathrm{s}$ & A & A & s & A & s & & A & s & $\mathrm{A}$ & s & A & s & s & A & $\mathrm{s}$ & A & s 1 , & & A & s & \\
\hline & Exame & e de escarro & 5 & A & $\mathrm{A}$ & s & A & s & A & A & s & A & s & \begin{tabular}{l|l}
$\mathrm{A}$ \\
\end{tabular} & s & 5 & A & $\mathrm{s}$ & A & s. & & A & $s$ & \\
\hline & Glicem & & $\mathrm{s}$ & A & A & $\mathrm{s}$ & A & s & A & A & s & A & $\mathrm{s}$ & A & 5 & $\mathrm{~s}$ & A & s & A & $\mathrm{s}$ & & A & $\mathrm{s}$ & A \\
\hline \& & HDL & & 5 & A & A & $\mathrm{s}$ & A & s & A & \begin{tabular}{l|l}
$S$ & $A$ \\
\end{tabular} & s & A & 5 & A & 5 & s & A & s & A & s. & & 5 & $\mathrm{~s}$ & \\
\hline & Hemas & globina glicada & 5 & A & A & 5 & A & s & A & \begin{tabular}{l|l}
$S$ & $A$ \\
\end{tabular} & 5 & A & 5 & A & 5 & s & A & $\mathrm{s}$ & A & s & & 5 & 5 & A \\
\hline & Hemor & grama & $\mathrm{s}$ & A 5 & A & s & A & s & A & \begin{tabular}{l|l}
$S$ & $A$ \\
\end{tabular} & $s$ & A & s & A & s & s & A & $\mathrm{s}$ & A & s & & s & s & A \\
\hline 离 & $\mathrm{LDL}$ & & s & \begin{tabular}{l|l} 
A & s \\
\end{tabular} & A & s & A & s & A & \begin{tabular}{l|l|}
$S$ & $A$ \\
\end{tabular} & $\mathrm{~s}$ & A & s & A & $\mathrm{s}$ & $s$ & A & s & A & \begin{tabular}{l|l}
$s$ & 1 \\
\end{tabular} & & s & 5 & A \\
\hline$\dot{n}$ & Retino & ografia/Fundo de olho com oftalmologista & $\mathrm{s}$ & A 5 & A & s & A & 5 & A & A & $\mathrm{s}$ & A & $\mathrm{s}$ & A & s & $\mathrm{s}$ & A & s & A & $\mathrm{s}$ & & s & 5 & $\mathrm{~A}$ \\
\hline . & Sorola & ogia de sifflis (VDRL) & s & \begin{tabular}{l|l} 
& $S$ \\
\end{tabular} & A & s & A & s & A & A & s & $\mathrm{A}$ & s & A & s & s & A & $\mathrm{s}$ & A & s & & 5 & $s$ & A \\
\hline 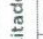 & Sorolo & ogia para dengue & $s$ & $A S$ & $A$ & s & $A$ & $s$ & ${ }_{A}$ & A & s & $\mathrm{A}$ & $s$ & A & 5 & s & A & s & A & $s$ & & $\mathrm{~s}$ & $\mathrm{~s}$ & A \\
\hline 䇏 & Soroto & ogia para HIV & s & \begin{tabular}{l|l} 
& $s$ \\
\end{tabular} & A & s & A & 5 & A & A & s & A & s & A & s & 5 & A & $\mathrm{s}$ & A & s & & $s$ & $\mathrm{~s}$ & A \\
\hline $\bar{\omega}$ & Teste i & indireto de antiglobulina humana (TIA) & 5 & A $\mathrm{s}$ & A & s & A & s & A & A & s & $\mathrm{A}$ & s & A & 5 & s & A & $\mathrm{s}$ & A & $\mathrm{s}$ & & $\mathrm{s}$ & $\mathrm{s}$ & A \\
\hline 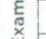 & Testec & de gravidez & s & $\begin{array}{ll}A & s \\
\end{array}$ & A & s & A & 5 & A & A & 5 & A & s & A & s & 5 & A & 5 & A & $s$ & & 5 & 5 & A \\
\hline & Ultrass & ssonografia obstétrica & s & \begin{tabular}{l|l} 
& 5 \\
\end{tabular} & A & 5 & A & s & A & A & s & A & $\mathrm{s}$ & A & 5 & s & A & $s$ & A & s & & A & $\mathrm{s}$ & A] \\
\hline & Urocul & ultura & 5 & $\begin{array}{ll}A & 5\end{array}$ & A & 5 & A & 5 & $A$ & $A$ & 5 & $\mathrm{~A}$ & 5 & A & 5 & $\mathrm{~s}$ & A & 5 & A & $s$ & & 5 & 5 & A \\
\hline & ED & Teste da orelhinha (EOA) & $s$ & $\begin{array}{ll}A \\
A\end{array}$ & $A$ & $\mathrm{~s}$ & $A$ & $\mathrm{~s}$ & A & A & 5 & A & $s$ & A & 5 & $s$ & A & 5 & A & $s$ & & A & 5 & A \\
\hline & 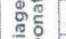 & Teste do olhinho (TRV) & $s$ & $\begin{array}{ll}\mathrm{A} \\
\mathrm{S}\end{array}$ & A & 5 & $A$ & 5 & A & \begin{tabular}{l|l}
$S$ & $A$ \\
\end{tabular} & s & $A$ & $\mathrm{~s}$ & A & $s$ & $s$ & $A$ & 5 & A & 5 & & A & $s$ & A \\
\hline & FE & Teste do pezinho & 5 & $\begin{array}{ll}\mathrm{A} \\
\mathrm{A}\end{array}$ & $A$ & s & $A$ & $s$ & A & \begin{tabular}{l|l}
$S$ & $A$ \\
\end{tabular} & s & $A$ & 5 & $\mathrm{~A}$ & 5 & $s$ & A & s & A & 5 & & $s$ & 5 & $\mathrm{~A}$ \\
\hline & & $-1 \ldots 1-1-1-1+1-1-1-1$ & $\mathrm{~s}$ & \begin{tabular}{l|l} 
A & $s$ \\
\end{tabular} & A & $\mathrm{s}$ & A & s & A & \begin{tabular}{l|l}
$S$ & $A$ \\
\end{tabular} & s & A & s & A & s & s & A & s & A & s & & s & s & A \\
\hline & 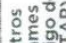 & L I I I I I I I I I I I I I I & s & A 5 & A & $s$ & A & $s$ & \begin{tabular}{l|l} 
& $S$ \\
\end{tabular} & \begin{tabular}{l|l}
$S$ & $A$ \\
\end{tabular} & s & A & s & A & s & & A & 5 & $A$ & s & & 5 & s & $A$ \\
\hline & 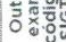 & 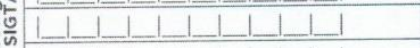 & s & A & A & s & A & s & A $\mathrm{A}$ & \begin{tabular}{l|l} 
S & A \\
\end{tabular} & s & A & s & A & s & & A & s & A & s & & s & $s$ & $A$ \\
\hline & & 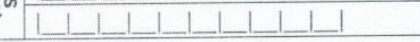 & \begin{tabular}{l|l} 
\\
\end{tabular} & $\begin{array}{ll}A & \end{array}$ & \begin{tabular}{l|l}
5 & $A$ \\
\end{tabular} & s & A & 5 & $A$ & \begin{tabular}{l|l}
$S$ & $A$
\end{tabular} & 5 & A & s & A & s & & A & $\mathrm{s}$ & A & \begin{tabular}{l|l} 
s & $A$ \\
\end{tabular} & & \begin{tabular}{l|l}
$S$ & $A$ \\
\end{tabular} & s & A \\
\hline & $\mathrm{sem}$ & Observaçāo? & & & $194 N A \bar{O}$ & & NĀOO & $\sin 4$ & $\overrightarrow{A O}$ & SMMNAC & SIM & NAOO & & NÄO: & $\sin N \operatorname{Na}^{-1}$ & & NäO & & NAO: & $\operatorname{SIM} N \bar{A}$ & & Simpä́ & & \\
\hline$\div$ & Avalia & acão/Diagnóstico & 约 & & $\dot{0}$ & & 3 & L & & $\square$ & & 7 & & 3 & $\square$ & & 0 & & $\underline{2}$ & $\square$ & & $\square$ & & \\
\hline$\frac{2}{n}$ & Proces & dimentos Clinicos/Terapèutico & & & $\square$ & & ] & $\square$ & & $\square$ & & 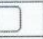 & & 5 & $\square$ & & $\square$ & & $\supseteq$ & $\square$ & & $\square$ & $\equiv$ & \\
\hline$\frac{\pi_{0}^{\circ}}{2}$ & Prescr & ricăo terapêutica & 0 & & 0 & & 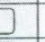 & $\square$ & & $\square$ & & $\square$ & & & $\square$ & & $\square$ & & ] & $\square$ & & $\square$ & & \\
\hline & Retorn & no para consulta agendada & $\square$ & & $\square$ & & $\supseteq$ & $\square$ & & 0 & & 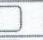 & & & $\square$ & & $\square$ & & 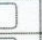 & $\square$ & & $\square$ & & \\
\hline & Retorn & no $\mathrm{p} /$ cuidado continuado/programado & 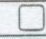 & & 0 & & $?$ & $\square$ & & $\square$ & & 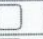 & & ] & $\square$ & & $\square$ & & $\supseteq$ & $\square$ & & $\square$ & & \\
\hline & Agend & damento para grupos & & & $\square$ & & ] & $\square$ & & $\square$ & & $\supseteq$ & & ] & $\square$ & & $\square$ & & $\supseteq$ & $\square$ & & $\square$ & & \\
\hline & Agend & damento $p /$ NASF & $\underline{n}$ & & $\square$ & & 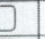 & $\square$ & & $\square$ & & $\square$ & $\equiv$ & ] & $\square$ & & $\square$ & & $\supseteq$ & $\square$ & & $\square$ & & \\
\hline$\frac{0}{8}$ & Alta d & do episódio & $\underline{\underline{2}}$ & & $\square$ & 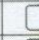 & ] & $\square$ & & $\square$ & & $\square$ & $\equiv$ & ] & $\square$ & & $\square$ & & 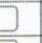 & $\square$ & & $\square$ & 4 & \\
\hline & & Encaminhamento interno no dia & $\equiv$ & & $\square$ & C & ] & $\square$ & & $\square$ & & $\theta$ & & ] & $\square$ & & $\square$ & & 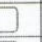 & $\square$ & & $\square$ & 5 & \\
\hline 苞 & : & Encaminhamento $\mathrm{p}$ / serviço especializado & 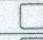 & & $\square$ & [ & $?$ & $\square$ & & $\square$ & & $\square$ & & & $\square$ & & 0 & & 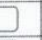 & 0 & & $\square$ & L & \\
\hline 党 & हू. & Encaminhamento $p /$ CAPS & 童 & & $\square$ & C & 了 & 口 & & $\square$ & & 0 & & 7 & $\square$ & & $\square$ & & 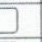 & $\square$ & & $\square$ & E & \\
\hline 0 & 疍 & Encaminhamento $p /$ internaçăo hospitalar & 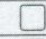 & & $\square$ & [ & 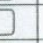 & $\square$ & & $\square$ & & $\square$ & & 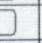 & $\square$ & & $\square$ & & 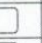 & $\square$ & & 0 & [ & \\
\hline & ह & Encaminhamento $\mathrm{p} /$ urgência & $\square$ & & $\square$ & c & & $\square$ & & $\square$ & & 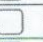 & & 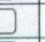 & $\square$ & & $\square$ & & J & $\square$ & & $\square$ & 5 & \\
\hline & 总 & Encaminhamento $p /$ serviço de Atencăo Domicliar & E & & $\square$ & {[} & & 口 & & $\square$ & & $\square$ & L & 卫 & $\square$ & & $\square$ & & 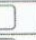 & $\square$ & & $\square$ & 5 & \\
\hline & & Encaminhamento intersetorial & E & & $\square$ & {[} & 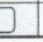 & $\square$ & & $\square$ & & $\square$ & [ & & $\square$ & & $\square$ & & ] & & & $\square$ & & \\
\hline
\end{tabular}

Legenda: $\square$ Opcão múltipla de escolha $\bigcirc$ Opção única de escolha (marcar $X$ na opção desejada)

Local de Atendimento: 01 - UBS 02-Unidade móvel 03-Rua 04-Domicilio 05 - Escola/Creche 06 - Outros 07 - Polo (Academia da Saúde) 08-Instituicăo/Abrigo 09 - Unidade prisional ou congêneres 10- Unidade socioeducativa Aleitamento materno: 01 - Exclusivo 02 - P

3-Complementado 04 - Inexistente Racionalidade em saúde: 01 - Medicina Tradicional Chinesa O2 Antroposofia Aplicada a Saude Modalida patla $A D$ : destinada a Modalidade de AD: destinada a usuários com diculade ou regularmente pela equipe de Atenção Básica. AD2: usuários que necessitam de cuidado intensivo. cuiclados de menor intensidade, devendo ser acompan criterios de $A D 2$ somados ao uso de suporte ventilatório não invasivo, ou paracentese, ou diálise peritoneal * Campo obrigatório 


\section{ANEXO C - CONVITE COREN/SP}

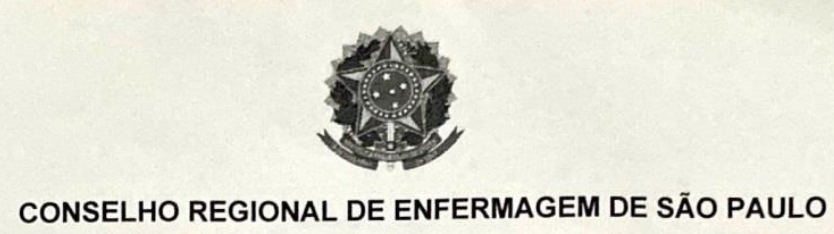

São Paulo, 21 de janeiro de 2020.

Prezado(a) Senhor(a),

Atendendo as últimas diretivas do Tribunal de Contas da União (TCU), da Procuradoria Geral da União e do Ministério Público (MPF) pertinente ao escopo das Autarquias Federais Fiscalizadoras do exercício profissional, temos a informar que o apoio deste Conselho Regional na trajetória do estudo ocorre da seguinte forma:

O "link" do estudo é divulgado aos profissionais de enfermagem com cadastro atualizado e válido por meio do envio de e-mail marketing disparado uma única vez sem garantir o alcance da totalidade esperada.

Há estudos que demonstram que apenas $2 \%$ dos destinatários concluem as ações pretendidas nas mensagens.

Identificamos a aprovação do estudo pela Instituição de Ensino, credenciada pela Comissão Nacional de Ensino e Pesquisa (CONEP), mas será obrigatória também a apresentação do Termo de Consentimento Livre e Esclarecido (TCLE), ante a divulgação da pesquisa.

O profissional Pesquisador deve estar com o registro no COREN ativo, requisito que você já atende, e as recomendações supracitadas devem ser seguidas. Garantiremos o sigilo das informações cadastrais dos profissionais.

O estudo, quando finalizado, deve ser encaminhando aos cuidados do Coren-SP. sua requisição.

Aguardamos seu posicionamento frente ao exposto, para que possamos dar continuidade a

Atenciosamente,

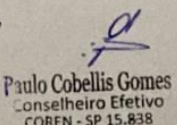
Juliana Baraldi Ferrareze Secretária $\mathrm{GAB}$

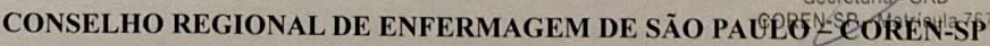




\section{ANEXO D - TERMO DE CONSENTIMENTO LIVRE E ESCLARECIDO - QUESTIONÁRIO ONLINE}

Convido o $\operatorname{Sr}(a)$ a participar da pesquisa intitulada "O conhecimento e o uso da Classificação Internacional da Atenção Primária por Enfermeiros da Atenção Primária à Saúde” desenvolvida pela Sra. Isis Arcanjo Colucci da Silva, responsável pela pesquisa, enfermeira e mestranda do Programa de Pós-Graduação Mestrado Profissional em Enfermagem na Atenção Primária no Sistema Único de saúde (MPAPS) da Escola de Enfermagem da Universidade de São Paulo. Esta pesquisa está sob a orientação da Profa. Dra. Anna Luiza de Fátima Pinho Lins Gryscheck, do Departamento de Enfermagem em Saúde Coletiva dessa mesma Escola.

O objetivo da pesquisa é identificar o conhecimento e uso da Classificação Internacional da Atenção Primária pelos enfermeiros que atuam na Atenção Primária à Saúde.

A técnica utilizada para coleta de dados será por meio de questionário online através da ferramenta Google Forms.

Sua participação nesta pesquisa limitar-se-á a responder a um questionário, com os seguintes aspectos: caracterização pessoal e questões sobre o conhecimento e uso da Classificação Internacional de Atenção Primária. O tempo estimado para a o preenchimento é de 10 minutos. Sua participação nesta pesquisa trará como benefício geral, o maior conhecimento sobre o tema abordado, o reconhecimento da realidade sobre o conhecimento da Classificação Internacional de Atenção Primária, não apresenta benefício direto para você.

O possível risco oferecido com a participação nesta pesquisa é que pode gerar desconforto por ter que se posicionar quanto ao conhecimento e uso da Classificação Internacional da Atenção Primária e para isso será considerado os princípios de privacidade, confiança e respeito. Diante de eventuais danos decorrentes da pesquisa você será indenizado.

A participação é voluntária sem qualquer tipo de custo ou remuneração e você tem a liberdade de desistir em qualquer momento da pesquisa caso deseje, sem qualquer tipo de prejuízo ou sanção. Caso tenha alguma despesa devido a pesquisa será ressarcido pelo próprio pesquisador.

Gostaria de convidá-lo(a) a participar desta pesquisa, destacando a importância de sua colaboração ativa para o aprofundamento da compreensão sobre o tema. Por ocasião de divulgação dos resultados será garantido seu anonimato e o sigilo de seus dados confidenciais. Após a finalização da investigação, se houver interesse, você terá livre acesso a seu conteúdo, podendo discuti-lo com o pesquisador. 
A pesquisa atende todas as especificações da Resolução 466, de 12 de dezembro de 2012 que aprova as diretrizes e normas regulamentadoras de pesquisas envolvendo seres humanos.

Se você concordar em participar, deverá indicar no final do formulário eletrônico que leu o TCLE e que aceita participar desta pesquisa. Após o aceite em participar da pesquisa será solicitado que você preencha seus dados em um formulário sem identificação com algumas informações sobre sua formação acadêmica e atuação profissional.

Caso sinta necessidade de qualquer esclarecimento em qualquer etapa do estudo, poderá entrar em contato com a pesquisadora Sra. Isis Arcanjo Colucci da Silva que pode de ser encontrada no endereço Rua Dr. Hélio Fidélis nº 26 apt. 85 G Bairro Vila São Francisco Cidade: São Paulo- SP. Telefone: (11) 99718-7371 e-mail: isisarcanjo@usp.br.

Caso você tenha alguma consideração ou dúvida sobre a ética da pesquisa, ou queira realizar alguma denúncia, entre em contato com os Comitês de Ética em Pesquisa (CEP) que são responsáveis pela avaliação e acompanhamento dos aspectos éticos de todas as pesquisas envolvendo seres humanos: Comitê de Ética em Pesquisa da Secretaria Municipal da Saúde CEP/SMS Rua General Jardim, 36 - $1^{\circ}$ andar Informações/ dúvidas: Fone: 3397-2464 • e-mail: smscep@gmail.com; e Comitê de Ética em Pesquisa da Escola de Enfermagem da Universidade de São Paulo- Av. Dr. Enéas de Carvalho Aguiar, 419 - Cerqueira Cesar - São Paulo/SP CEP -05403-000 Telefone- (11) 3061-8858 e-mail - cepee@ usp.br. 


\section{ANEXO E - CAPACITAÇÃO PARA CONHECIMENTO E APLICABILIDADE DO CIAP}

A Atenção Primária à Saúde se expandiu e se consolidou nos últimos anos.

Os profissionais capacitados e com determinadas competências são cada vez mais necessários e requisitados para melhores resultados no cuidado das pessoas.

Diante deste cenário, este curso visa instrumentalizar o aluno a utilizar a CIAP de forma adequada podendo usar as informações geradas a partir da clínica para a gestão dos processos de trabalho.

A capacitação será oferecida por EAD, o conteúdo das aulas será disponibilizado, as aulas estarão distribuídas em 3 módulos, divididos por tópicos centrais que são essenciais para a compreensão do tema proposto visando que ao fim desta capacitação, os profissionais envolvidos realizar as classificações em CIAP de forma adequada e utilizem estes dados para a Gestão da sua Clínica.

\section{Objetivos Pedagógicos:}

- Conhecer a evolução histórica da CIAP

- Entender o porquê utilizar a classificação em CIAP

- Compreender a estrutura da CIAP

- Conhecer e desenvolver a habilidade de manusear o livro da CIAP e seu resumo

- Reconhecer os momentos que podemos classificar (SOAP)

- Avaliar as relações entre os momentos avaliados

\section{Público Alvo:}

Alunos de graduação, residentes e profissionais da saúde com interesse em atenção primária.

\section{Programa:}

Módulo 1 - Evolução histórica da CIAP (carga horária: 2 horas)

- Conferência de Alma Ata

- Atenção Primária à Saúde e seus atributos

- Classificação dos Motivos de Consulta

- A CIAP no mundo

Módulo 2 - Estrutura da CIAP e forma de utilização (carga horária 3 horas)

- Sumário da CIAP: forma de organização das informações e aplicabilidade

- Livro CIAP: como realizar consulta para inclusão ou exclusão de determinada classificação

- Legislação

Módulo 3 - Casos clínicos para o desenvolvimento da prática (carga horária 4 horas)

- SOAP 
- Método Clínico centrado na pessoa

- Através de casos clínicos realizaremos a Classificação dos momentos da consulta em CIAP

- Gestão da Clínica a partir dos dados gerados em CIAP

\section{Referências que serão utilizadas}

Araújo LN, Figueira MD. Gestão da clínica. In: Valladão Júnior JBR, Gusso G, Olmos RD, editores. Medicina de família e comunidade. Rio de Janeiro: Atheneu; 2017. p. 3-22.

Basílio N, Ramos C, Figueira S, Pinto D. Worldwide usage of International Classification of Primary Care. Rev Bras Med Fam Comunidade [Internet]. 2016 [cited 2020 Jan 20];11(38):19. Available from: https://rbmfc.org.br/rbmfc/article/view/1225/769. DOI: https://doi.org/10.5712/rbmfc11(38)1225.

Bousquat A, Giovanella L, Campos EMS, Almeida PF, Martins CL, Mota PHS, et al. Atenção primária à saúde e coordenação do cuidado nas regiões de saúde: perspectiva de gestores e usuários. Cien Saude Colet [Internet]. 2017 [cited 2019 Jan 20];22(4): 1141-54. Available from: https://www.scielo.br/pdf/csc/v22n4/1413-8123-csc-22-04-1141.pdf. DOI: https://doi.org/10.1590/1413-81232017224.28632016.

Brasil. Conselho Nacional de Secretários de Saúde. Atenção primária e promoção da saúde [Internet]. Brasília: CONASS; 2015 [cited 2019 Jan 20]. Available from: https://www.conass.org.br/biblioteca/pdf/atualizacao-2015/L03_ATENCAO-PRIMARIA-ASAUDE_jun2015.pdf

Brasil. Conselho Nacional de Secretários de Saúde. Atenção primária e promoção da saúde [Internet]. Brasília: CONASS; 2015 [cited 2019 Jan 20]. Available from: https://www.conass.org.br/biblioteca/pdf/atualizacao-2015/L03_ATENCAO-PRIMARIA-ASAUDE_jun2015.pdf

Brasil. Ministério da Saúde, Universidade Federal de Santa Catarina. e-SUS atenção básica: sistema com coleta de dados simplificada - CDS: manual do digitador [Internet]. Brasília: Ministério da Saúde, 2013 [cited 2019 Jan 20]. Available from: http://189.28.128.100/dab/docs/portaldab/documentos/manual_digitador.pdf

Casajuana J, Bellón J. La gestión de la consulta en atención primaria. In: Martin Zurro A, Cano-Pérez J, editores. Atención primaria: conceptos, organización y práctica clínica. $5^{\mathrm{a}}$ ed. Madrid: Elsevier; 2003. p. 84-109.

Comitê Internacional de Classificação da WONCA. Classificação Internacional de Atenção Primária (CIAP2) [Internet]. $2^{\mathrm{a}}$ ed. Florianópolis: Sociedade Brasileira de Medicina de Família e Comunidade; 2009 [cited 2020 Jan 20]. Available from:

http://www.sbmfc.org.br/wpcontent/uploads/media/file/CIAP\%202/CIAP\%20Brasil_atualizado.pdf

Gusso GDF, Poli Neto P. Gestão da clínica. In: Gusso GDF, Lopes JMC, editores. Tratado de medicina de família e comunidade. Porto Alegre: Artmed; 2012. p. 159-65. 
Gusso GDF. Diagnóstico de demanda em Florianópolis utilizando a Classificação Internacional de Atenção Primária: $2^{\mathrm{a}}$ ed. (CIAP-2) [dissertação] [Internet]. São Paulo: Faculdade de Medicina, Universidade de São Paulo; 2009 [cited Jan 20]. Available from: https://www.teses.usp.br/teses/disponiveis/5/5159/tde-08032010164025/publico/GustavoGusso.pdf

Landsberg GAP, Savassi LCM, Sousa AB, Freitas JMR, Nascimento JLS, Azagra R. Análise de demanda em Medicina de Família no Brasil utilizando a Classificação Internacional de Atenção Primária. Cien Saude Colet [Internet]. 2012 [cited 2020 Jan 20];17(11):1-8. Available from: https://www.scielo.br/pdf/csc/v17n11/v17n11a18.pdf. DOI; https://doi.org/10.1590/S1413-81232012001100019.

Lebrão ML. Classificação internacional de motivos de consulta para assistênciaprimária: teste em algumas áreas brasileiras. Rev Saude Publica [Internet]. 1985 [cited 2020 Jan 20];19(1):69-78. Available from: https://www.scielo.br/pdf/rsp/v19n1/08.pdf. DOI; https://doi.org/10.1590/S0034-89101985000100008.

Martin Zurro A, Cano-Pérez J, editores. Atención primaria: conceptos, organización y práctica clínica. $5^{\text {a }}$ ed. Madrid: Elsevier; 2003.

Mendes EV. As redes de atenção à saúde [Internet]. Brasília: Organização Pan-Americana da Saúde; 2011 [cited 2019 Jan 20]. Available from:

https://www.paho.org/bra/index.php?option=com_docman\&view=download\&category_slug= servicos-saude-095\&alias=1402-as-redes-atencao-a-saude-2a-edicao- 2 \&Itemid=965

Orozco Beltrán D, Pedrera Carbonell V, Gil Guillén V, Prieto Erades I, Ribera Montés MC, P. Martínez Cánovas. Gestión clínica de la consulta: Previsibilidad y contenido clínico (Estudio SyN-PC). Aten Primaria [Internet]. 2004 [cited 2019 Jan 20];33(2):69-77. Available from: https://www.elsevier.es/es-revista-atencion-primaria-27-articulo-gestion-clinicaconsulta-previsibilidad-contenido-13057254

Santiago LM, Carvalho R, Botas P, Miranda P, Matias C, Simões AR, et al. A informação na consulta presencial em Medicina Geral e Familiar: classificações segundo a ICPC-2 e anotações livres para a memória futura no SOAP. Rev Bras Med Fam Comunidade [Internet]. $30^{\circ}$ de setembro de 2015 [cited 2020 Jan 20];10(36). Disponível em:

https://rbmfc.org.br/rbmfc/article/view/840. DOI: https://doi.org/10.5712/rbmfc10(36)840.

Santos KPB, Ribeiro MTAM. Motivos de consulta mais comuns das pessoas atendidas por uma equipe de saúde da família em Fortaleza - CE. Rev Bras Med Fam Comunidade [Internet]. 30 de dezembro de 2015 [cited 2020 Jan 20];10(37):1-11. Disponível em: https://rbmfc.org.br/rbmfc/article/view/831. DOI: https://doi.org/10.5712/rbmfc10(37)831.

Sociedad Española de Medicina de Familia y Comunitaria. Medidas concretas para la desburocratización de las consultas de Atención Primaria [Internet]. Barcelona: semFYC; 2008 [cited 2020 Jan 20]. Available from: https://www.semfyc.es/wpcontent/uploads/2016/04/2008.-DOCU-25-DESBRUROCRATIZACI\%C3\%93N.pdf

Soler J, Okkes I, Wood M, Lamberts H. The coming of age of ICPC: celebrating the 21 st birthday of the International Classification of Primary Care. Fam Pract [Internet]. 2008 [cited 2020 Jan 20];25(4):312-7. Available from: 
https://academic.oup.com/fampra/article/25/4/312/604241. DOI:

https://doi.org/10.1093/fampra/cmn028.

Starfield B. Atenção primária: equilíbrio entre necessidades de saúde, serviços e tecnologia [Internet]. Brasília: UNESCO; 2002 [cited 2020 Jan 20]. Available from:

https://www.nescon.medicina.ufmg.br/biblioteca/imagem/0253.pdf

Starfield B. Is primary care essential? Lancet [Internet]. 1994 [cited 2020 Jan 20];344(8930):1129-33. Available from:

https://www.sciencedirect.com/science/article/abs/pii/S0140673694906343. DOI:

https://doi.org/10.1016/S0140-6736(94)90634-3. 